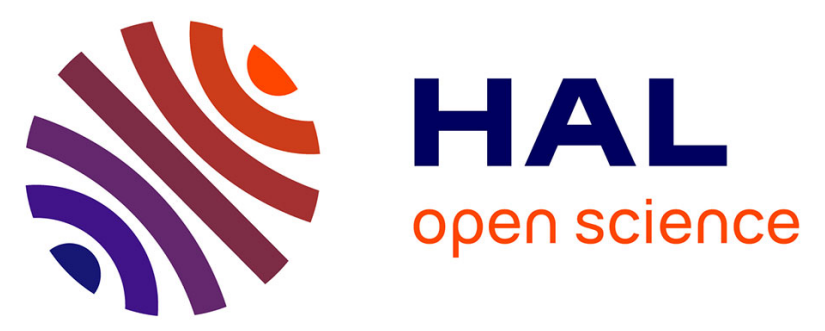

\title{
EMMA, a cost and time-effective diagnostic method for simultaneous detection of point mutations and large-scale genomic rearrangements: application to BRCA1 and BRCA2 in 1,525 patients.
}

Virginie Caux-Moncoutier, Laurent Castera, Carole Tirapo, Dorothée Michaux, Marie-Alice Remon, Anthony Laugé, Etienne Rouleau, Antoine de Pauw, Bruno Buecher, Marion Gauthier-Villars, et al.

\section{- To cite this version:}

Virginie Caux-Moncoutier, Laurent Castera, Carole Tirapo, Dorothée Michaux, Marie-Alice Remon, et al. EMMA, a cost and time-effective diagnostic method for simultaneous detection of point mutations and large-scale genomic rearrangements: application to BRCA1 and BRCA2 in 1,525 patients.. Human Mutation, 2011, 32 (3), pp.325. 10.1002/humu.21414 . hal-00613913

\section{HAL Id: hal-00613913 https://hal.science/hal-00613913}

Submitted on 8 Aug 2011

HAL is a multi-disciplinary open access archive for the deposit and dissemination of scientific research documents, whether they are published or not. The documents may come from teaching and research institutions in France or abroad, or from public or private research centers.
L'archive ouverte pluridisciplinaire HAL, est destinée au dépôt et à la diffusion de documents scientifiques de niveau recherche, publiés ou non, émanant des établissements d'enseignement et de recherche français ou étrangers, des laboratoires publics ou privés. 


\section{Human Mutation}

WILEY

\section{EMMA, a cost and time-effective diagnostic method for simultaneous detection of point mutations and large-scale genomic rearrangements: application to BRCA1 and BRCA2 in 1,525 patients.}

\begin{tabular}{|c|c|}
\hline Journal: & Human Mutation \\
\hline Manuscript ID: & humu-2010-0378.R1 \\
\hline Wiley - Manuscript type: & Methods \\
\hline $\begin{array}{l}\text { Date Submitted by the } \\
\text { Author: }\end{array}$ & 18 -Oct-2010 \\
\hline Complete List of Authors: & $\begin{array}{l}\text { Caux-Moncoutier, Virginie; Institut Curie, génétique } \\
\text { Castera, Laurent; Institut Curie, Génétique } \\
\text { Tirapo, Carole; Institut Curie, Génétique } \\
\text { Michaux, Dorothée; Institut Curie, génétique } \\
\text { Remon, Marie-Alice; Institut Curie, Génétique } \\
\text { Laugé, Anthony; Institut Curie, génétique } \\
\text { ROULEAU, Etienne; Centre René Huguenin, Laboratoire } \\
\text { d'Oncogénétique } \\
\text { DE Pauw, Antoine; Institut Curie, Génétique } \\
\text { Buecher, Bruno; Institut Curie, Génétique } \\
\text { Gauthier-Villars, Marion; Institut Curie, génétique } \\
\text { Viovy, Jean-Louis; Institut Curie, physico chimie } \\
\text { Stoppa-Lyonnet, Dominique; Institut Curie } \\
\text { Houdayer, Claude; Institut Curie, Génétique; Université Paris 5, } \\
\text { Faculté de Pharmacie, génétique }\end{array}$ \\
\hline Key Words: & $\begin{array}{l}\text { BRCA1, BRCA2, mutation, screening, diagnosis, capillary } \\
\text { electrophoresis }\end{array}$ \\
\hline
\end{tabular}

\section{SCHOLARONE Manuscripts}


EMMA, a cost- and time-effective diagnostic method for simultaneous detection of point mutations and large-scale genomic rearrangements: application to $B R C A 1$ and $B R C A 2$ in 1,525 patients.

Virginie Caux-Moncoutier, ${ }^{1}$ Laurent Castéra, ${ }^{1}$ Carole Tirapo, ${ }^{1}$ Dorothée Michaux, ${ }^{1}$ MarieAlice Rémon, ${ }^{1}$ Anthony Laugé, ${ }^{1}$ Etienne Rouleau, ${ }^{2}$ Antoine De Pauw, ${ }^{1}$ Bruno Buecher, ${ }^{1}$ Marion Gauthier-Villars, ${ }^{1}$ Jean-Louis Viovy, ${ }^{3}$ Dominique Stoppa-Lyonnet, ${ }^{1,4,5}$ Claude Houdayer $^{1,5^{*}}$

${ }^{1}$ Service de Génétique Oncologique, Institut Curie, Paris, France

${ }^{2}$ Laboratoire d'Oncogénétique, Institut Curie, Saint-Cloud, France

${ }^{3}$ Laboratoire Physicochimie-Curie, Institut Curie, Paris, France

${ }^{4}$ INSERM U830, Pathologie Moléculaire des Cancers, Institut Curie, Paris, France

${ }^{5}$ Université Paris Descartes, Paris, France

(*) Author for correspondence:

Claude Houdayer, Pharm.D, Ph.D

Service de Génétique Oncologique, Institut Curie, 75005 Paris, France

e-mail: claude.houdayer@ curie.net

Phone: 33-1 44324698

Fax: $\quad 33-153102648$ 


\begin{abstract}
The detection of unknown mutations remains a serious challenge and, despite the expected benefits for the patient's health, a large number of genes are not screened on a routine basis. We present the diagnostic application of EMMA (Enhanced Mismatch Mutation Analysis®, Fluigent), a novel method based on heteroduplex analysis by capillary electrophoresis using innovative matrices. $B R C A 1$ and $B R C A 2$ were screened for point mutations and large rearrangements in 1,525 unrelated patients (372 for the validation step and 1,153 in routine diagnosis) using a single analytical condition. Seven working days were needed for complete $B R C A 1 / 2$ screening in 30 patients by one technician (excluding DNA extraction and sequencing). A total of 137 mutations were found, including a BRCA2 duplication of exons 19 and 20, previously missed by Comprehensive BRACAnalysis ${ }^{\circledR}$. The mutation detection rate was $11.9 \%$, which is consistent with patient inclusions.

This study therefore suggests that EMMA represents a valuable short-term and midterm option for many diagnostic laboratories looking for an easy, reliable and affordable strategy, enabling fast and sensitive analysis for a large number of genes.
\end{abstract}

\title{
Key words:
}

BRCA1, BRCA2, mutation, screening, diagnosis, capillary electrophoresis, EMMA 


\section{INTRODUCTION}

The role of genetic screening is becoming increasingly important in cancer diagnosis, prognosis and treatment decisions. Developing fast, reliable and inexpensive methods to detect such mutations is therefore a major challenge for medicine.

Two main strategies are used to search for unknown mutations: direct sequencing and screening. The first strategy is currently considered to be the most reliable, although not totally flawless (Eng, et al., 2001). More specifically, reliable chemistry and software are prominent points to consider.

The second strategy is a two-step strategy involving preliminary screening for the presence of variants on amplicons, followed by sequencing of only those fragment(s) in which a variation was detected. This dramatically reduces the number of fragments that need to be sequenced. These screening strategies are mainly based on heteroduplex analysis (HDA), using either a dedicated liquid chromatographic system (Denaturing High Performance Liquid Chromatography, DHPLC)(Spiegelman, et al., 2000) or a real-time PCR machine (High Resolution Melting curve analysis, HRM)(Wittwer, 2009). During a slow cool-down performed at the end of PCR amplification of a DNA fragment from a heterozygote sample, two homoduplex fragments (corresponding to the normal and mutated allele, respectively) and two heteroduplexes (with mismatched strands due to hybridization of a wild-type strand with a mutant strand) are obtained. The aim of HDA is to check for the presence of heteroduplexes. DHPLC and HRM are widely used in diagnostic laboratories. However, analysis conditions depend on melting domains, and optimization is required for each PCR fragment.

HDA can also be performed by electrophoresis: homoduplexes are separated from heteroduplexes due to differences in electrophoretic mobility. Separations are nowadays 
mostly performed by multi-capillary electrophoresis, allowing for high automation, low cost and high throughput, as recently described in a diagnostic validation of ConformationSensitive Capillary Electrophoresis (Mattocks, et al.) . A novel HDA method has been recently developed (Houdayer, et al.2010). This method, called Enhanced Mismatch Mutation Analysis (EMMA) is based on the use of innovative matrices increasing the electrophoretic mobility differences between homoduplex and heteroduplex DNA (Weber, et al., 2004). Sensitivity is further improved by using nucleosides as additives to enhance single-base substitution detection. Nucleosides are expected to interact with mismatched bases of heteroduplexes, thereby increasing mobility differences with homoduplexes (Weber, et al., 2006). Moreover, this method, in combination with adapted semiquantitative PCR conditions, can be used to simultaneously detect point mutations and large-scale rearrangement in a single run (Weber, et al., 2007). This feature, combined with the use of a single set of separation conditions for all fragments and with the multiplexing capability of the method, leads to a considerable simplification and cost reduction compared to previous methods.

The use of EMMA for fast screening of $B R C A 1$ and $B R C A 2$ point mutations and large rearrangements is described below. Constitutional mutations of the BRCA1 [MIM 113705] and BRCA2 [MIM 600185] genes are associated with a risk of hereditary breast and ovarian cancer (HBOC). It is essential to identify BRCA1/2 mutations to provide appropriate counseling to patients and relatives, but this represents a challenging and time-consuming task, as the vast majority of mutations are unique and spread over the entire coding sequence. In this paper, we report the results of $B R C A 1$ and $B R C A 2$ screening for point mutations and large rearrangements in 1,525 unrelated patients (372 for the validation step and 1,153 in routine diagnosis), and discuss the performance of this new strategy. 


\section{PATIENTS AND METHODS}

\section{Patients}

Genetic testing for $B R C A 1$ and $B R C A 2$ was proposed to women based on individual and/or family history (herein defined as index cases i.e. the first family member in whom complete BRCA1/2 gene screening was performed). Individual inclusion criteria included: i) breast adenocarcinoma before the age of 36 , ii) medullary adenocarcinoma without age limitation, iii) breast adenocarcinoma and ovarian cancer. Male breast cancer was also considered for genetic testing. Family history was defined as either i) 3 breast cancer cases in first- or second-degree relatives in the same lineage, ii) 2 breast cancer cases in first- or second-degree relatives (with a transmitting male), with one cancer before the age of 40 or one cancer before 50 and the other before 70 iii) 1 breast cancer case and one first- or second-degree relative (with a transmitting male) with ovarian cancer. During the course of this study, and in line with French recommendations, inclusion criteria were recently extended to women with isolated ovarian adenocarcinoma before the age of 70 (http://www.e-cancer.fr/lessoins/oncogenetique). A consecutive series of 1,525 ascertained cases, mostly of Caucasian descent, were studied. All patients attended a visit with a geneticist and a genetic counselor in a family cancer clinic, mostly at the Institut Curie, Paris, France. Patients gave their informed consent for BRCA1/2 gene analyses. .

\section{Nucleic acid extraction}

For mutation scanning purposes, DNA was extracted from $2 \mathrm{ml}$ whole blood samples collected on EDTA using a modified perchlorate/chloroform procedure (first 465 samples), as 
previously described(Johns and Paulus-Thomas, 1989), or the NucleoSpin blood L kit from Macherey Nagel (following 849 samples) or the Quickgene 610-L automated system from FujiFilm (last 211 samples) according to the manufacturer's instructions. Three different extraction procedures were used during this study in the context of a constant effort to reduce the time and labor involved, finally leading to the semi-automated solution from FujiFilm. DNAs were calibrated to $50 \mathrm{ng} / \mu \mathrm{l}$ by UV spectrophotometric assay (Nanodrop). Absorbance ratios (260/280) and (260/230) had to be in the 1.8-2.0 and 2.0-2.2 ranges, respectively.

\section{Enhanced Mismatch Mutation Analysis (EMMA)}

Primer design. Primers were purchased from Fluigent, Paris, France. BRCAl and BRCA2 coding sequences were divided into 81 amplicons analyzed in 24 multiplex PCRs including one internal control for large-scale rearrangement analysis (Primer sequences are available from Fluigent). Primers were designed to include flanking intronic sequences containing recognized splice sites and avoiding known polymorphism to prevent mispriming. Due to the well-known limitations of capillary electrophoresis (Rozycka, et al., 2000) and topological effects (Weber, et al., 2004), false-negatives can occur in the 70bp from both extremities of the amplicon. As a result, larger and overlapping amplicons were designed so that the sequence of interest always fell outside these 70bp in at least one amplicon (Weber, et al., 2006). One primer of each pair was labeled with 6-carboxyfluorescein (6-FAM).

Amplicon synthesis. Primer mixes were prepared according to the manufacturer's instructions (Fluigent) and all multiplex PCRs were performed using a single condition with the Qiagen Multiplex PCR kit (Qiagen, Courtaboeuf, France). Briefly, samples were generated in a $10-\mu \mathrm{l}$ reaction volume containing $100 \mathrm{ng}$ of genomic DNA, $1 \mu$ li.e. $0.3 \mu \mathrm{M}$ of 
primer mix (Fluigent), $2 \mu$ l of water and $5 \mu$ l i.e. $1 \mathrm{X}$ Qiagen Multiplex PCR Master mix supplied by the manufacturer (Qiagen). The PCR programs were run in a GeneAmp 9700 thermocycler (Applied Biosystems, Courtaboeuf, France) and consisted of a first denaturation step at $95^{\circ} \mathrm{C}$ for $15 \mathrm{~min}$, followed by 23 cycles of denaturation at $94^{\circ} \mathrm{C}$ for $30 \mathrm{~s}$, annealing at $58^{\circ} \mathrm{C}$ for $90 \mathrm{~s}$ and extension at $72^{\circ} \mathrm{C}$ for $90 \mathrm{~s}$, followed by a final extension at $72^{\circ} \mathrm{C}$ for 10 min. PCR products were denatured for $5 \mathrm{~min}$ at $96^{\circ} \mathrm{C}$ then gradually reannealed at $-1^{\circ} \mathrm{C} / \mathrm{min}$ to reach $25^{\circ} \mathrm{C}$. On completion of PCR, PCR products were stored at $-20^{\circ} \mathrm{C}$ until migration.

Analysis. PCR tube volume was completed with pure water up to $20 \mu \mathrm{L}$. Wells in columns $\mathrm{A}$ and $\mathrm{H}$ were filled with $1 \mu \mathrm{L}$ EMMA buffer $10 \mathrm{x}$ to compensate for the higher intensity of the capillaries at the extremities of the area. PCRs were electrophoresed with a single analytical condition $\left(15 \mathrm{kV}\right.$ at $30^{\circ} \mathrm{C}$ and a fifty $\mathrm{cm}$ length-to-detector array) on an ABI3100 (Applied Biosystems) using EMMA polymer and according to the manufacturer's instructions (Fluigent, Paris, France). Data were analyzed using dedicated software (Emmalys, Fluigent). Electrophoregrams were examined and scored by two operators.

Point mutations. PCR products showing abnormal EMMA profiles (e.g. multiple peaks, shouldering or peak widening) were re-amplified, purified and sequenced in both directions using the BigDye Terminator Cycle Sequencing V1.1 Ready Reaction kit (Applied Biosystems) with incorporation of the PCR oligonucleotides as extension primers, followed by electrophoresis in an ABI PRISM 3130XL Genetic Analyzer with analysis using the Collection and Sequence Analysis software package (Applied Biosystems). Nucleotide position was numbered on the basis of the coding sequence NM_007294.2 and NM_000059.3 for $B R C A 1$ and $B R C A 2$, respectively. Nucleotide numbering reflects cDNA numbering with +1 corresponding to the $\mathrm{A}$ of the ATG translation initiation codon in the reference sequence according to recommended guidelines (available at http://www.emqn.org/emqn.php and 
www.hgvs.org/mutnomen). The initiation codon is codon 1. Electrophoregrams were examined and scored by two operators. All mutations were confirmed on a second blood or buccal swab sample.

Large rearrangements. EMMA and quantitative multiplex PCR of short fluorescent fragments (QMPSF) were both used to screen for $B R C A 1$ and $B R C A 2$ rearrangements because automated profile analysis was easier with QMPSF (see below). QMPSF was used as previously described (Casilli, et al., 2006) . All rearrangements were confirmed on a second blood sample and using another technique e.g. long range PCR, transcript analysis or a dedicated array-CGH (Rouleau, et al., 2007) . Spurious single-exon deletions due to mispriming were therefore unambiguously excluded.

\section{Unknown Variants (UVs) interpretation}

In silico analysis. Unfortunately, one half of the variations observed in the BRCA1/2 genes are UVs (Hofstra, et al., 2008), making biological and clinical interpretation a challenging task and consequently leading to clinically difficult situations. To facilitate subsequent genetic counseling, all identified UVs were submitted to in silico analysis using Alamut (Interactive Biosoftware), a decision-support system for mutation interpretation that integrates a splice prediction module. Apart from the impact on splicing, unknown variants were also analyzed for their putative "protein-based" impact by cross-species and Grantham score (Grantham, 1974) comparisons, and were then scored using an in-house model (Supp. Figure S1) validated on a series of 378 hereditary breast/ovarian cancer patients and previous literature [unpublished data, available on request]. Variants were classified as neutral or of little clinical significance below 6 and worthy of complementary investigations (e.g. cosegregation analyses or functional studies) above 12. In such cases, the clinical context was also thoroughly discussed with the clinical geneticist. 
Transcript analysis. Patients harboring unknown variants putatively leading to splice defects following Alamut in silico analyses were further investigated at the cDNA level. Based on previous knowledge (Houdayer, et al., 2008), defects were defined as a minimum $10 \%$ decrease of the wild-type score. Emergence of a cryptic splice site was considered significant and worthy of RNA study when it scored at least $50 \%$ of the corresponding wildtype score. ESEs were not considered for routine purposes.

RNA was extracted from lymphoblastoid cell lines with and without puromycin treatment. RNA was reverse-transcribed (Houdayer, et al., 2004) and the BRCAl/2 coding sequence surrounding the region of interest was amplified (primer sequences available on request). Amplicons were purified and sequenced in both directions using the BigDye Terminator Cycle Sequencing V1.1 Ready Reaction kit (Applied Biosystems) with incorporation of the PCR oligonucleotides as extension primers, followed by electrophoresis in an ABI PRISM 3130XL Genetic Analyzer with analysis using the Collection and Sequence Analysis software package (Applied Biosystems). Normal controls were always included in these experiments. 


\section{RESULTS}

An EMMA-based strategy was designed for fast screening of BRCA1 and BRCA2 point mutations and large rearrangements in 1,525 unrelated hereditary breast and/or ovarian cancer (HBOC) patients: 1,153 patients were screened in a routine setting following a validation step enrolling 372 patients.

\section{Validation step}

Point mutations. Before implementing EMMA as a routine diagnostic technique, a panel of known BRCA mutations was tested (Weber, et al., 2004; Weber, et al., 2006) [and author's unpublished data]. A series of blind studies were then performed using DHPLC and QMPSF as reference techniques for point mutation and large rearrangement screening, respectively. DHPLC was chosen as a reference because it is considered to be the gold standard for mutation prescreening with more than 1,000 PubMed references [http://www.ncbi.nlm.nih.gov/sites/entrez]. Moreover, our laboratory has an extensive experience with this technique, with more than 4,000 patients screened for $B R C A 1 / 2$ and $R B 1$ point mutations (Houdayer, et al., 2004; Wagner, et al., 1999) and, more recently, large-scale rearrangements using the DHPLC-derived technique called MP/LC (Dehainault, et al., 2004). The blind studies involved a total of 372 patients. Two hundred and seventy nine cases were first screened on BRCAl by Fluigent in their mutation detection facility, and 93 cases were then screened on both $B R C A 1$ and $B R C A 2$ in our laboratory. PCR conditions and analyses were as described above. An equivalent sensitivity was demonstrated, as 127 variations (excluding polymorphisms) were found with both techniques. Actually, one variation was missed by EMMA (BRCA2, c.9364G>A/p.Ala3122Thr), but another variation missed by DHPLC was detected by EMMA (BRCA1, c.2311T>C/p.Leu771Leu). 
Large rearrangements. The principle of the method consists of quantitative evaluation of the relative proportion of a given fragment in the unknown sample with respect to a normal control. In order to compare two fragments amplified in two different tubes, peak intensities and areas are normalized to a non-mutated DNA fragment used as an internal control. Fluorescence intensities were then normalized by adjusting the peaks and areas obtained for the control amplicons to the same level and the yield of each amplicon in the various samples was evaluated. As some profiles exhibit variations due to polymorphisms, rare variants and mutations, Emmalys analyzes variant and non-variant profiles separately and deletions are detected by a $50 \%$ decrease in peak intensity and area, while duplications are detected by a 1.5-increase in profile area. Firstly, a 30-sample dedicated large rearrangement panel was blindly tested using this procedure. This panel included 20 BRCAl large rearrangements (deletions and duplications) and 10 normal controls. All samples were correctly scored. The second step of the validation consisted of identification of 3 large rearrangements present in the 372 patients. Two deletions encompassing exons 15 and 16 and 13 to 15 , respectively, were correctly detected. The third deletion, a deletion of $B R C A 1$ promoter, was not detected because the current EMMA primer panel does not explore this part of the gene (which is covered by our QMPSF assay).

\section{Interpretation of polymorphisms according to their profiles.}

One of the main challenges with prescreening methods is the correct identification of polymorphisms. This does not constitute an issue for genes with a very low polymorphic content such as $R B I$ but is a major hurdle for $B R C A$ genes, which exhibit a large number of polymorphisms throughout their sequence. In this case, the advantages of prescreening methods are lost if each variant peak has to be sequenced (Mattocks, et al. 2010). The situation becomes much simpler if the method allows correct recognition of polymorphisms according to their profile. This requires a high profile specificity and reproducibility. Profiles 
of distinct mutations from the same fragment must therefore be distinguished, and for the same variant, the same profile should be observed in independent experiments.

Reproducibility was evaluated within series and between series, by superimposition of profiles from the same variant. Profiles matched very accurately (Figures 1A, B). A high profile specificity was also observed, as illustrated e.g. Figure 2 illustrating 2 polymorphic profiles and the co-occurrence of these two polymorphisms in the same patient.

Polymorphisms were consequently expected to be identified from their variant profile. To validate this hypothesis, all variant profiles interpreted as polymorphisms in this series of 93 patients were sequenced (for a total of 1,200 sequences), and sequencing results were compared to EMMA interpretation. In every case, the expected polymorphism was found and no extra polymorphism was found in the remaining variant profiles, corresponding to a sensitivity and specificity of $100 \%$ in this series. To ensure correct interpretation, polymorphisms should be interpreted together and compared between each other instead of being compared to a normal control.

\section{Mutations Identified in Routine Screening}

DNAs from 1,153 hereditary breast/ovarian cancer patients were subjected to routine EMMA screening followed by sequencing of variant fragments. An average of 10 to $15 \%$ of PCRs had to be re-amplified due to low signal-to-noise ratio (see discussion section) and 3\% of variant amplicons were sequenced. The 137 mutations found are reported in Supp. Tables S1A-B. The overall mutational detection rate according to our inclusion criteria was $11.9 \%$ i.e. $6 \%$ and $5.9 \%$ on $B R C A 1$ and $B R C A 2$, respectively. The unknown variant detection rate (Supp. Table S2) was $33.5 \%$ i.e. higher than previously reported because of the length of the intronic sequences analyzed that includes a 70bp "safe zone" (see "primer design"). This increased number of intronic UVs may represent a drawback of the design which is why 
subsequent in silico splice analysis is recommended to confidently predict their putative impact on splicing. UV detection rate was approximately twofold higher in BRCA2 $(23.8 \%)$ than in $B R C A 1$ (9.7\%). This figure is explained by the respective length of their coding sequences, which in turn means that fewer mutations are found in $B R C A 2$ as compared to BRCA1.Mutations were similar in type and relative proportion in BRCA1 and BRCA2 (Table 1). They mainly resulted in truncated proteins or RNA decay. BRCA2 yielded a slightly higher rate of frameshift mutations, due to a greater number of frameshift deletions $(51.5 \% \mathrm{vs}$. $33.3 \%$ of the mutational spectrum for $B R C A 2$ and $B R C A 1$, respectively). Frameshift mutations are by far the largest class of mutations, followed by nonsense and splice mutations (average 20\% and 9\% for both genes). Other mutations comprised rare mutations, i.e. missense, in-frame and large rearrangements. Four large rearrangements were found on $B R C A 1$ and 2 on BRCA2. In other words, point mutations and large rearrangements accounted for $94.2 \%$ and $5.8 \%$ of the mutational spectrum of $B R C A 1$, respectively. For $B R C A 2$, point mutations accounted for $97.1 \%$ of the mutational spectrum whereas large rearrangements represented $2.9 \%$ of the mutational spectrum

The most frequent mutations found were c.5266dupC on BRCA1 and c.2808_2811del on BRCA2 (each found 6 times) followed by BRCA2 c.5946delT (4 times). Four other mutations were each found 3 times, i.e. c. $1 \mathrm{~A}>\mathrm{G}$, c.68_69del and c.4986+6T $>\mathrm{C}$ on $B R C A 1$ and c.1773_1776del on BRCA2. This lack of frequent mutations probably reflects the mixed ethnic origin of the study population derived from Paris and suburbs.

According to our criteria, 18 UVs putatively leaded to a splice anomaly. Lymphoblastoid cell lines were available in 10 cases and another blood sample has yet to be obtained from the remaining 8 cases. Two UVs on both $B R C A 1$ and $B R C A 2$ actually lead to a splice defect. The c. $547+3 \mathrm{~A}>\mathrm{T} / \mathrm{IVS} 08+3 \mathrm{~A}>\mathrm{T}$ and c. $4484 \mathrm{G}>\mathrm{T} / \mathrm{p} . \mathrm{Arg} 1495 \mathrm{Met}$ on BRCA1 showed decrease of the donor site with subsequent exon 8 and exon 14 skipping, respectively. The c.316+5G>C / 
IVS03 $+5 \mathrm{G}>\mathrm{C}$ and the c.7975A $>\mathrm{G} / \mathrm{p}$.Arg2659Gly on BRCA2 also showed decrease of the donor site with subsequent exon 3 and exon 17 skipping.

Apart from splicing, 3 other UVs were prominent protein-damaging candidates with scores greater than 16 i.e. c.92T>A/p.Ile31Asn and c.122C>T/p.Pro41Leu, c.280C>T/p.Pro94Ser on $B R C A 1$ and $B R C A 2$, respectively. They are included in class 4 of the recently proposed classification system (Plon, et al., 2008).

\section{Throughput}

Patients were initially analyzed by series of 96 , according to the same organization as previously used with DHPLC. Following a learning curve period, series of 30 patients were subsequently analyzed. It now takes seven working days for complete BRCA1/2 screening in 30 patients by one technician (excluding DNA extraction and sequencing). 


\section{DISCUSSION}

One thousand five hundred and twenty five unrelated breast and/or ovarian cancer patients were studied, as part of the routine clinical management provided by the Institut Curie, Paris, France. To our knowledge, this is the largest complete mutational screening of $B R C A 1 / 2$ genes reported to date in Europe.

\section{EMMA}

This is the first report of a large-scale study using EMMA, some aspects of this methodology therefore need to be discussed. Capillary electrophoresis was developed as an attractive strategy for mutation detection in the early 1990's (Khrapko, et al., 1994). However, its broad diffusion was hampered by design constraints and lack of sensitivity (Rozycka, et al., 2000). The recently described Heteroduplex Analysis by Capillary Array Electrophoresis (Perez-Cabornero, et al., 2009), also called Conformation-Sensitive Capillary Electrophoresis (CSCE)(Mattocks, et al. 2010) represents a real improvement, but it also presents certain disadvantages. It uses a home-made polymer recipe that does not allow batch-to-batch reproducibility. Consequently, all fragments with altered peak patterns need to be sequenced, dramatically increasing the amount of sequencing needed for genes such as BRCA1/2, which involve frequent polymorphisms; large rearrangements cannot be detected and mutational screening must be completed by another method.. EMMA retains the simplicity and throughput of CSCE, but as a result of a series of additional developmentscomprising industrialized ready-to-use separation matrix and specific software, it overcomes the above limitations. It allows easy and reliable recognition of polymorphisms according to their 
profile, and it is the first technique able to detect large rearrangements and point mutations in a single run (Weber, et al., 2007).

. Some technical remarks and guidelines for implementation and use, based on our experience, are listed below. Regarding DNA extraction, 3 different procedures were used during the course of the study (see Materials and Methods" section) without any incidence on data quality. Due to its high sensitivity, in order to take full advantage of the potential of the technique for direct polymorphism identification, specific PCR amplifications must be used since nonspecific products could generate shouldering for a wild-type sample, making the profile difficult to interpret. Nonspecific products may also be generated by primer degradation with time, but this is easily detected because profiles lose their reproducibility. Capillary electrophoresis always involves slight run-to-run and capillary-to-capillary mobility shifts, so it is therefore important to compare peaks after correct peak alignment, which can be tricky with conventional software in the case of complex profiles. The Emmalys software appeared to effectively deal with this difficulty, as suggested by the robustness of polymorphism analysis.

Strikingly, heteroduplexes could be either slower or faster than homoduplexes and no rule was found that could link one type of nucleotide substitution to one type of mobility difference or profile shape. Electrophoretic mobility does not only depend on the mismatch bases, but also on the local sequence environment of this mismatch, since distortions of the DNA helix at one base pair are propagated to the neighboring bases(Weber, et al., 2004). As a consequence of the above, a heteroduplex can exceptionally comigrate with the peak corresponding to the following/preceding peak in the multiplex electrophoregram. Therefore, if an amplicon from a patient shows an abnormal profile, but does not show any variation on sequencing, it could indicate that the altered amplicon is actually a neighboring amplicon. This can be easily confirmed by observing the result of large rearrangement analysis, which should in turn mimic a deletion on the neighboring peak. Similarly, the quantitative analysis 
used to detect large rearrangements can also be helpful to detect allele drop-out due to mispriming. This information is important in order to detect situations in which one allele would not be amplified and therefore not analyzed. Moreover, the nucleotide variation inducing the mispriming can also be deleterious. Obviously, in such a case another primer pair must be used to distinguish this allelic drop-out from a bona fide deletion.

Finally, to ensure reliable and easy interpretation of polymorphisms, it is recommended to work on series of 30 samples or more. Below this range, it may prove difficult to correctly interpret polymorphism profiles because of an insufficient number of reference profiles.

Distinct injection protocols are available to ensure optimum results (EMMA high-low). In a first, "low" injection mode, samples are injected for $10 \mathrm{~s}-20 \mathrm{~s}$ at $1 \mathrm{kV}-4 \mathrm{kV}$ then electrophoresed at $15 \mathrm{kV}$ for $45 \mathrm{~min}$. This injection mode has a sufficiently low consumption to allow a second run to be performed from the same sample using a "higher injection" protocol, in the event of occasional unexpected problems (missed injection, capillary failure, microbubble, etc). All of these "tricks", recommendations and checkpoints are summarized in the Analysis Pipeline, Figure 3.

The viscosity of EMMA separation medium is higher than that of other solutions conventionally used in ABI instruments. This requires certain modifications of the capillary filling and apparatus operation sequences (provided by Fluigent), compared to standard procedures. For instance, this involves longer array filling time, capillary rinsing with buffer every 100 runs, and capillary array exchange every 400 runs. Replacing EMMA buffer 1x daily is also recommended to avoid loss of resolution. System performance and integrity should be checked once a week using a control sample (a 4-plex PCR with variant profiles for each peak, available from Fluigent). As for any heteroduplex analysis, homozygous mutations cannot be detected by EMMA on the direct sample, but this can be circumvented by adding a wild-type DNA in the sample to force heteroduplex formation, as previously demonstrated with DHPLC (Ferec, et al., 2004). 
In addition to the above precautions and issues, which require the level of care typically required by molecular diagnosis, EMMA uses standard and well-known sequencers and a set of ready-to-use reagents, thereby facilitating upgrading to this new technology.

The cost of consumable items used to screen BRCA1 and BRCA2 by EMMA is estimated to be less than 100 euros per patient (based on price list). This estimation excluded the costs of DNA extraction and sequencing, purchase of the sequencer, instrument depreciation and labor. The markedly reduced need for downstream sequencing (typically 3\%), as a result of polymorphism identification, is also a factor for cost reduction (Sevilla, et al., 2002). This technology allows a high throughput and our laboratory now generates close to 9000 amplicons per month for diagnostic purposes; it should be stressed that the management of such a large volume of data requires a robust data management system. We have therefore constructed a FileMakerPro® database which integrates information from sampling to the final report, but which also interacts with the Institute's databases. This allows careful followup of the entire analysis [Laugé A et al., poster 664 Assises de Génétique 2010].

The advantages of EMMA compared to our previous DHPLC-based strategy are obvious: they comprise a single condition for amplification and run, a higher throughput and lower costs (lab technician time decreased to one quarter and overall cost decreased to one third, compared to DHPLC in our hands). The simultaneous detection of point mutations and large rearrangements is another advantage. However promoter regions are not covered and this must be taken into account, since deletions of the promoter regions are a probably rare but significant cause of HBOC (Brown, et al., 2002; Caux-Moncoutier, et al., 2009). Although technical performance was acceptable, the complexity of the currently available Emmalys interface prevents routine use of large rearrangement detection. On the other hand, Emmalys was found to be robust and user-friendly for point mutation detection. 
More generally, we believe EMMA should be considered as an alternative to the High Resolution Melting curve analysis (HRM) technique. HRM is a very fast and elegant tubemethod also allowing simultaneous detection of point mutations and large rearrangements in one experiment (Coulet, et al., 2010 ; Rouleau, et al., 2009). Its main advantage over EMMA is the absence of post-PCR manipulation. However, based on the recent literature, HRM appears to have a number of drawbacks (which are overcome by EMMA), notably:

i) its sensitivity depends on the nucleotide composition of the amplicon (melting domains). HRM diagnostic guidelines for $B R C A 1$ screening recommend extreme caution when analyzing high-GC, low-GC contents and fragments containing many different variants (van der Stoep, et al., 2009; Wittwer, 2009)

ii) interpretation of polymorphisms according to their profile would need probes or sequence analysis to exclude the presence of a mutation with an identical melt profile(Nguyen-Dumont, et al., 2009).

\section{Spectrum of Mutations}

The mutation detection rate in $B R C A$ genes largely depends on the patient inclusion criteria and selecting high-risk patients from breast and ovarian families would provide the geneticist with a higher mutation detection rate than including patients based exclusively on their personal history. That being said, the sensitivity of EMMA was $11.9 \%$ in our series of 1,153 patients, which is in line with expectations with regards to patient inclusions and compared to previous results using DHPLC as well as data from French laboratories (http://www.e-cancer.fr).

Considering the mutational spectrum, the recurrent so-called Ashkenazim mutations (BRCA1 68_69del, 5266dupC and BRCA2 5946delT) represented 9.5\% of our identified mutations, which is why prescreening for these 3 mutations is proposed during genetic counseling to 
patients reporting an Eastern European origin. Apart from these mutations, we did not observe a larger panel of recurrent mutations which would justify a first-line screening procedure, as described in other populations (Revillion, et al., 2004). Few deleterious inframe/missenses mutations were found but this could actually reflect an interpretation bias in view of the fact that 386 unknown variants were detected (detection rate 33.5\%). In other words, these 386 variants no doubt included deleterious neutral/missense/intronic mutations, which is why scoring variants to highlight prominent candidates for future collaborative studies is of special relevance for optimization of molecular diagnosis. There is considerable debate about the usefulness of large rearrangement screening in $B R C A$ genes. The main argument against such screening, is that the time and efforts needed for such screening might be used more efficiently by screening more patients but for point mutations only. Previous reports (Engert, et al., 2008; Mazoyer, 2005)suggested that large rearrangements accounted for an average of $10 \%$ of the BRCAl mutational spectrum. Although our present results are lower (5.8\%), we can confidently confirm that it is worth searching for $B R C A l$ large rearrangements in genetic diagnosis, regardless of the patient's family history. The situation is less clear for BRCA2 because previous studies, including those from our team (Casilli, et al., 2006; Tournier, et al., 2004), were based on smaller series and selected high-risk families (Agata, et al., 2005; Engert, et al., 2008; Woodward, et al., 2005). These studies led to the overall conclusion that $B R C A 2$ genomic rearrangements are worth investigating in high-risk families. This does not mean that these mutations are associated with a higher risk, but that due to the very low contribution of large rearrangements in the $B R C A 2$ mutational spectrum, the search for these mutations should be limited to patients with a severe family history associated with a high $B R C A 2$ mutation detection rate. Two $B R C A 2$ large rearrangements, one complete deletion and one duplication of exons 19, 20 (Figure 4) were found in the present series of 1,153 consecutive patients. The deletion was found in a young breast cancer patient with no family history i.e. a low-risk case. Conversely, the duplication was found in a high-risk family: the 
index case and her older sister developed bilateral breast carcinoma at 48, 64 and 57, 63 years of age, respectively. Their paternal aunt and grandmother also developed breast cancer at 45 and 61 years of age, respectively. The overall probability of identifying a $B R C A$ mutation in our index case was $59.4 \%$ (24.6\% for BRCA1 and $34.9 \%$ for $B R C A 2)$ according to the BRCAPRO model (Parmigiani, et al., 1998) and 57.9\%(12.1\% for BRCAl and $45.8 \%$ for BRCA2) according to the BOADICEA model (Antoniou, et al., 2008). Interestingly, her older affected sister was found to be negative using a combination of direct sequencing for BRCA1/2 and a limited 5-site rearrangement panel for BRCA1(Comprehensive BRACAnalysis®, Myriad® Genetics laboratories Inc. Salt Lake City, USA). Following identification of the BRCA2 duplication in our index case, genetic testing and appropriate genetic counseling were made available to the relatives e.g. 6 unaffected females (at least) and the affected sister. As expected, the affected sister carried the BRCA2 duplication. More generally, and as this kind of mutation might also be found in low-risk situations, this study argues in favor of methods allowing simultaneous and convenient detection of point mutations and large rearrangements to enable clinical geneticists to meet the constraints of routine genetic testing.

\section{General conclusions and perspectives}

The main advantages of EMMA are that it provides a marked increase of throughput (or cost reduction at a given throughput) compared to DHPLC and is based on standard sequencers routinely used in laboratories. It can therefore be easily implemented in laboratories familiar with capillary electrophoresis, and allows screening and sequencing on the same platform. Due to its flexibility, EMMA could also be used for rapid $B R C A$ screening of a subset of patients e.g. before poly(ADP-ribose) polymerase inhibitor treatment (Audeh, et al., 2010 ; Tutt, et al. 2010). 
Finally, the future of EMMA should be considered in the context of growing sequencing capacities provided by the next-generation-sequencing (NGS) platforms. Since 2 SOLiD NGS platforms (ABI-Life technologies) are available in our Institute, we tested this technology for BRCA diagnostic applications [Houdayer $\mathrm{C}$ et al., European Society of Human Genetics meeting 2010, P11.089]. The SOLiD chemistry appears to be reliable for diagnostic purposes, but implementation of a SOLiD diagnostic pipeline remains complex at the present time for reasons of sample preparation, bioinformatics, fast-evolving protocols and costs. EMMA obviously cannot compete with SOLiD in terms of throughput, but indeed only a small number of diagnostic laboratories actually need such amazing sequencing capacities. The throughput and therefore data handling constraints of the 454 NGS machine (Roche) are still enormous, although lower than those of SOLiD, but well known sensitivity/specificity problems in homopolymer runs have to be taken into account (Emrich, et al., 2007; Wicker, et al., 2006). The present study therefore suggests that EMMA represents a valuable short-term and medium-term option for many diagnostic laboratories looking for an easy, reliable and affordable strategy, enabling fast and sensitive analysis for a large number of genes. 


\section{Acknowledgements}

The authors would like to thank J. Weber, J. Champ, C. Bureau, P. Michel, I. Eugène, C.

Gilbon, S. Miglierina and C. Rougeron for helpful support during the course of this study, as well as O. Béra, F. Cornelis, P. Laurent-Puig and I. Mortemousque for referring patients.

This paper describes work conducted in the context of the PREDICAN and Polygen projects.

PREDICAN is a collaborative project supported by Medicen and la Région Ile de France.

Polygen is supported by ANR (Agence Nationale pour la Recherche).

\section{Commercial interest:}

The EMMA technology is dependent on Curie Institute/CNRS/University Pierre et Marie Curie joint patents

DSL and JLV are shareholders of Fluigent 


\section{REFERENCES}

Agata S, Dalla Palma M, Callegaro M, Scaini MC, Menin C, Ghiotto C, Nicoletto O, Zavagno G, Chieco-Bianchi L, D'Andrea E and others. 2005. Large genomic deletions inactivate the BRCA2 gene in breast cancer families. J Med Genet 42(10):e64.

Antoniou AC, Cunningham AP, Peto J, Evans DG, Lalloo F, Narod SA, Risch HA, Eyfjord JE, Hopper JL, Southey MC and others. 2008. The BOADICEA model of genetic susceptibility to breast and ovarian cancers: updates and extensions. Br J Cancer 98(8):1457-66.

Audeh MW, Carmichael J, Penson RT, Friedlander M, Powell B, Bell-McGuinn KM, Scott C, Weitzel JN, Oaknin A, Loman N and others. 2010. Oral poly(ADP-ribose) polymerase inhibitor olaparib in patients with BRCA1 or BRCA2 mutations and recurrent ovarian cancer: a proof-of-concept trial. Lancet 376(9737):245-251.

Brown MA, Lo LJ, Catteau A, Xu CF, Lindeman GJ, Hodgson S, Solomon E. 2002. Germline BRCA1 promoter deletions in UK and Australian familial breast cancer patients: Identification of a novel deletion consistent with BRCA1:psiBRCA1 recombination. Hum Mutat 19(4):435-42.

Casilli F, Tournier I, Sinilnikova OM, Coulet F, Soubrier F, Houdayer C, Hardouin A, Berthet $\mathrm{P}$, Sobol H, Bourdon V and others. 2006. The contribution of germline rearrangements to the spectrum of BRCA2 mutations. J Med Genet 43(9):e49.

Caux-Moncoutier V, Pages-Berhouet S, Michaux D, Asselain B, Castera L, De Pauw A, Buecher B, Gauthier-Villars M, Stoppa-Lyonnet D, Houdayer C. 2009. Impact of BRCA1 and BRCA2 variants on splicing: clues from an allelic imbalance study. Eur J Hum Genet 17(11):1471-80.

Coulet F, Pires F, Rouleau E, Lefol C, Martin S, Colas C, Cohen-Haguenauer O, Giurgea I, Fajac A, Nogues C and others. 2010. A One-Step Prescreening for Point Mutations and Large Rearrangement in BRCA1 and BRCA2 Genes Using Quantitative Polymerase Chain Reaction and High-Resolution Melting Curve Analysis. Genet Test Mol Biomarkers.

Dehainault C, Lauge A, Caux-Moncoutier V, Pages-Berhouet S, Doz F, Desjardins L, Couturier J, Gauthier-Villars M, Stoppa-Lyonnet D, Houdayer C. 2004. Multiplex PCR/liquid chromatography assay for detection of gene rearrangements: application to RB1 gene. Nucleic Acids Res 32(18):e139.

Emrich SJ, Barbazuk WB, Li L, Schnable PS. 2007. Gene discovery and annotation using LCM-454 transcriptome sequencing. Genome Res 17(1):69-73.

Eng C, Brody LC, Wagner TM, Devilee P, Vijg J, Szabo C, Tavtigian SV, Nathanson KL, Ostrander E, Frank TS. 2001. Interpreting epidemiological research: blinded comparison of methods used to estimate the prevalence of inherited mutations in BRCA1. J Med Genet 38(12):824-33.

Engert S, Wappenschmidt B, Betz B, Kast K, Kutsche M, Hellebrand H, Goecke TO, Kiechle M, Niederacher D, Schmutzler RK and others. 2008. MLPA screening in the BRCA1 gene from 1,506 German hereditary breast cancer cases: novel deletions, frequent 
involvement of exon 17, and occurrence in single early-onset cases. Hum Mutat 29(7):948-58.

Ferec C, Le Marechal C, Audrezet MP, Farinha CM, Amaral MD, Gallati S, Sanz J, Steiner B, Mouchel N, Harris A and others. 2004. Analysis of genomic CFTR DNA. J Cyst Fibros 3 Suppl 2:7-10.

Grantham R. 1974. Amino acid difference formula to help explain protein evolution. Science 185(4154):862-4.

Hofstra RM, Spurdle AB, Eccles D, Foulkes WD, de Wind N, Hoogerbrugge N, Hogervorst FB. 2008. Tumor characteristics as an analytic tool for classifying genetic variants of uncertain clinical significance. Hum Mutat 29(11):1292-303.

Houdayer C, Dehainault C, Mattler C, Michaux D, Caux-Moncoutier V, Pages-Berhouet S, d'Enghien CD, Lauge A, Castera L, Gauthier-Villars M and others. 2008. Evaluation of in silico splice tools for decision-making in molecular diagnosis. Hum Mutat 29(7):975-82.

Houdayer C, Gauthier-Villars M, Lauge A, Pages-Berhouet S, Dehainault C, CauxMoncoutier V, Karczynski P, Tosi M, Doz F, Desjardins L and others. 2004. Comprehensive screening for constitutional RB1 mutations by DHPLC and QMPSF. Hum Mutat 23(2):193-202.

Houdayer C, Moncoutier V, Champ J, Weber J, Viovy JL, Stoppa-Lyonnet D. 2010. Enhanced mismatch mutation analysis: simultaneous detection of point mutations and large scale rearrangements by capillary electrophoresis, application to BRCA1 and BRCA2. Methods Mol Biol 653:147-80.

Johns MB, Jr., Paulus-Thomas JE. 1989. Purification of human genomic DNA from whole blood using sodium perchlorate in place of phenol. Anal Biochem 180(2):276-8.

Khrapko K, Hanekamp JS, Thilly WG, Belenkii A, Foret F, Karger BL. 1994. Constant denaturant capillary electrophoresis (CDCE): a high resolution approach to mutational analysis. Nucleic Acids Res 22(3):364-9.

Mattocks CJ, Watkins G, Ward D, Janssens T, Bosgoed EA, van der Donk K, Ligtenberg MJ, Pot B, Theelen J, Cross NC and others. 2010. Interlaboratory diagnostic validation of conformation-sensitive capillary electrophoresis for mutation scanning. Clin Chem 56(4):593-602.

Mazoyer S. 2005. Genomic rearrangements in the BRCA1 and BRCA2 genes. Hum Mutat 25(5):415-22.

Nguyen-Dumont T, Calvez-Kelm FL, Forey N, McKay-Chopin S, Garritano S, GioiaPatricola L, De Silva D, Weigel R, Sangrajrang S, Lesueur F and others. 2009. Description and validation of high-throughput simultaneous genotyping and mutation scanning by high-resolution melting curve analysis. Hum Mutat 30(6):884-90.

Parmigiani G, Berry D, Aguilar O. 1998. Determining carrier probabilities for breast cancersusceptibility genes BRCA1 and BRCA2. Am J Hum Genet 62(1):145-58.

Perez-Cabornero L, Velasco E, Infante M, Sanz D, Lastra E, Hernandez L, Miner C, Duran M. 2009. A new strategy to screen MMR genes in Lynch Syndrome: HA-CAE, MLPA and RT-PCR. Eur J Cancer 45(8):1485-93.

Plon SE, Eccles DM, Easton D, Foulkes WD, Genuardi M, Greenblatt MS, Hogervorst FB, Hoogerbrugge N, Spurdle AB, Tavtigian SV. 2008. Sequence variant classification and reporting: recommendations for improving the interpretation of cancer susceptibility genetic test results. Hum Mutat 29(11):1282-91.

Revillion F, Verdiere A, Fournier J, Hornez L, Peyrat JP. 2004. Multiplex single-nucleotide primer extension analysis to simultaneously detect eleven BRCA1 mutations in breast cancer families. Clin Chem 50(1):203-6.

Rouleau E, Lefol C, Bourdon V, Coulet F, Noguchi T, Soubrier F, Bieche I, Olschwang S, Sobol H, Lidereau R. 2009. Quantitative PCR high-resolution melting (qPCR-HRM) curve analysis, a new approach to simultaneously screen point mutations and large 
rearrangements: application to MLH1 germline mutations in Lynch syndrome. Hum Mutat 30(6):867-75.

Rouleau E, Lefol C, Tozlu S, Andrieu C, Guy C, Copigny F, Nogues C, Bieche I, Lidereau R. 2007. High-resolution oligonucleotide array-CGH applied to the detection and characterization of large rearrangements in the hereditary breast cancer gene BRCA1. Clin Genet 72(3):199-207.

Rozycka M, Collins N, Stratton MR, Wooster R. 2000. Rapid detection of DNA sequence variants by conformation-sensitive capillary electrophoresis. Genomics 70(1):34-40.

Sevilla C, Moatti JP, Julian-Reynier C, Eisinger F, Stoppa-Lyonnet D, Bressac-de Paillerets B, Sobol H. 2002. Testing for BRCA1 mutations: a cost-effectiveness analysis. Eur J Hum Genet 10(10):599-606.

Spiegelman JI, Mindrinos MN, Oefner PJ. 2000. High-accuracy DNA sequence variation screening by DHPLC. Biotechniques 29(5):1084-90, 1092.

Tournier I, Paillerets BB, Sobol H, Stoppa-Lyonnet D, Lidereau R, Barrois M, Mazoyer S, Coulet F, Hardouin A, Chompret A and others. 2004. Significant contribution of germline BRCA2 rearrangements in male breast cancer families. Cancer Res 64(22):8143-7.

Tutt A, Robson M, Garber JE, Domchek SM, Audeh MW, Weitzel JN, Friedlander M, Arun B, Loman N, Schmutzler RK and others. 2010. Oral poly(ADP-ribose) polymerase inhibitor olaparib in patients with BRCA1 or BRCA2 mutations and advanced breast cancer: a proof-of-concept trial. Lancet 376(9737):235-244.

van der Stoep N, van Paridon CD, Janssens T, Krenkova P, Stambergova A, Macek M, Matthijs G, Bakker E. 2009. Diagnostic guidelines for high-resolution melting curve (HRM) analysis: an interlaboratory validation of BRCA1 mutation scanning using the 96-well LightScanner. Hum Mutat 30(6):899-909.

Wagner T, Stoppa-Lyonnet D, Fleischmann E, Muhr D, Pages S, Sandberg T, Caux V, Moeslinger R, Langbauer G, Borg A and others. 1999. Denaturing high-performance liquid chromatography detects reliably BRCA1 and BRCA2 mutations. Genomics 62(3):369-76.

Weber J, Barbier V, Pages-Berhouet S, Caux-Moncoutier V, Stoppa-Lyonnet D, Viovy JL. 2004. A high-throughput mutation detection method based on heteroduplex analysis using graft copolymer matrixes: application to Brca1 and Brca2 analysis. Anal Chem 76(16):4839-48.

Weber J, Looten R, Houdayer C, Stoppa-Lyonnet D, Viovy JL. 2006. Improving sensitivity of electrophoretic heteroduplex analysis using nucleosides as additives: Application to the breast cancer predisposition gene BRCA2. Electrophoresis 27(8):1444-52.

Weber J, Miserere S, Champ J, Looten R, Stoppa-Lyonnet D, Viovy JL, Houdayer C. 2007. High-throughput simultaneous detection of point mutations and large-scale rearrangements by CE. Electrophoresis 28(23):4282-8.

Wicker T, Schlagenhauf E, Graner A, Close TJ, Keller B, Stein N. 2006. 454 sequencing put to the test using the complex genome of barley. BMC Genomics 7:275.

Wittwer CT. 2009. High-resolution DNA melting analysis: advancements and limitations. Hum Mutat 30(6):857-9.

Woodward AM, Davis TA, Silva AG, Kirk JA, Leary JA. 2005. Large genomic rearrangements of both BRCA2 and BRCA1 are a feature of the inherited breast/ovarian cancer phenotype in selected families. J Med Genet 42(5):e31. 


\section{FiguRE LEGENDS}

\section{Figure 1A. Reproducibility between series.}

Screenshot from Emmalys showing superimposition of 5 different samples harboring the same polymorphism (BRCA2 exon 2), from 5 different series of 93 patients.

\section{Figure 1B. Reproducibility within series.}

Screenshot from Emmalys showing superimposition of 33 different samples harboring the same polymorphism (BRCA1 exon 13), from a series of 93 patients.

\section{Figure 2. Profile specificity}

Screenshots from Emmalys with 3 polymorphic profiles from 2 adjacent codons (BRCA1 exon 11). In grey: normal monomorphic profile, in black: polymorphic profiles. From left to right: c.2077G >A/p.Asp693Asn, c.2082C >T/p.Ser694Ser and the combination of both (c.2077G >A/p.Asp693Asn plus c.2082C>T/p.Ser694Ser). All polymorphic profiles are clearly distinct.

Figure 3. EMMA : analysis pipeline

Schematic representation of a routine EMMA analysis.

Figure 4. Duplication of $B R C A 2$ exons 19 and 20.

Three screenshots from Emmalys showing the 3 multiplex PCRs incorporating BRCA2 exons 19 and 20 (panels A, B and C). Exons under study and the amplicon number (when the exon is investigated in overlapping amplicons) are indicated at the top of the corresponding peaks. The electrophoregrams in grey and black represent a normal control and the duplicated patient, respectively. Profiles are superimposed then normalized using the internal control.Two ratios are used to determine the presence or absence of a large-scale rearrangement: R1 is the ratio between peak intensity of the fragment of interest over peak intensity of the internal control. R2 (indicated for each peak) is the ratio of R1 of the sample of interest over control R1 defined as a mean R1 value based on several control samples. Duplicated exons are indicated by an arrow. Exon 19 is investigated in 2 overlapping amplicons (upper panels A, B), while exon 20 is investigated with a single amplicon (bottom panel C). 
Tables

Table 1. Deleterious mutations found according to their type.

\begin{tabular}{lcc} 
& BRCA1 (number and \%) & BRCA2 (number and \%) \\
\hline Frameshift & $37(53.6 \%)$ & $47(69.1 \%)$ \\
\hline Nonsense & $16(23.2 \%)$ & $13(19.1 \%)$ \\
\hline Splice & $8(11.6 \%)$ & $4(5.9 \%)$ \\
\hline Large rearrangements & $4(5.8 \%)$ & $2(2.9 \%)$ \\
\hline $\begin{array}{l}\text { Missense } \\
\text { Mutation detection rate }\end{array}$ & $4(5.8 \%)$ & $1(1.5 \%)$ \\
\hline In frame & $0(0 \%)$ & $1(1.5 \%)$ \\
\hline Total & $6(\mathbf{1 0 0 \%})$ & $\mathbf{6 8}(\mathbf{1 0 0 \%})$ \\
\hline
\end{tabular}




1
2
3
4
5
6
7
8
9
10
11
12
13
14
15
16
17
18
19
20
21
22
23
24
25
26
27
28
29
30
31
32
33
34
35
36
37
38
39
40
41
42
43
44
45
46
47
48
49
50
51
52
53
54
55
56
57
50

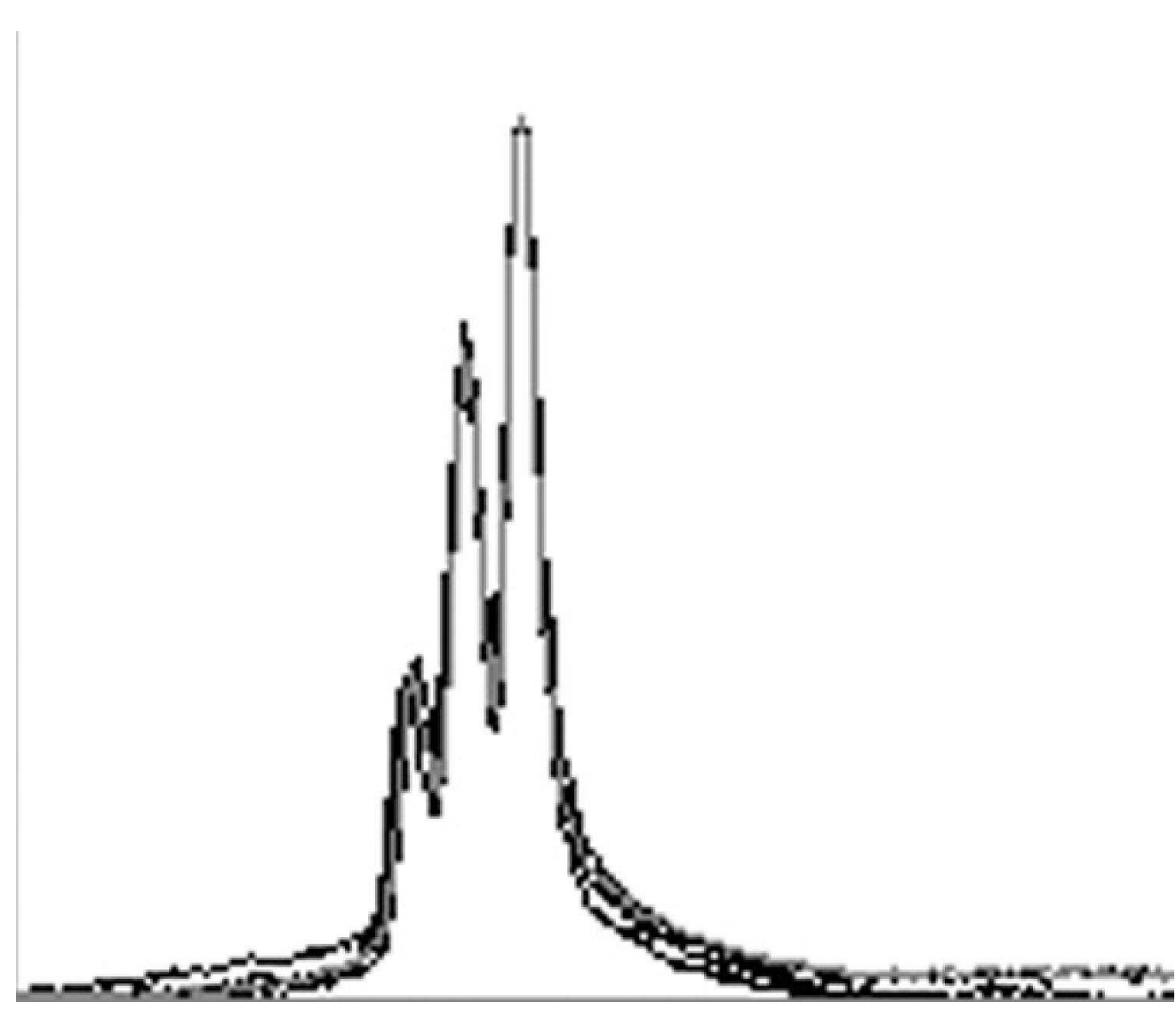

$63 \times 53 \mathrm{~mm}(600 \times 600$ DPI $)$

37

38

39

40

41

42

43
44

45

46

47

48

49

51

52

53

54

55

57

58

59

60

John Wiley \& Sons, Inc. 


$$
\mu
$$


Page 33 of 47

Human Mutation

\begin{tabular}{l}
1 \\
2 \\
3 \\
4 \\
5 \\
6 \\
7 \\
8 \\
9 \\
10 \\
11 \\
12 \\
13 \\
14 \\
15 \\
16 \\
17 \\
18 \\
19 \\
20 \\
21 \\
22 \\
23 \\
24 \\
25 \\
26 \\
27 \\
28 \\
29 \\
30 \\
31 \\
32 \\
33 \\
34 \\
35 \\
36 \\
37 \\
38 \\
39 \\
40 \\
41 \\
42 \\
43 \\
44 \\
45 \\
46 \\
47 \\
48 \\
59 \\
50 \\
51 \\
53 \\
5 \\
\hline
\end{tabular}

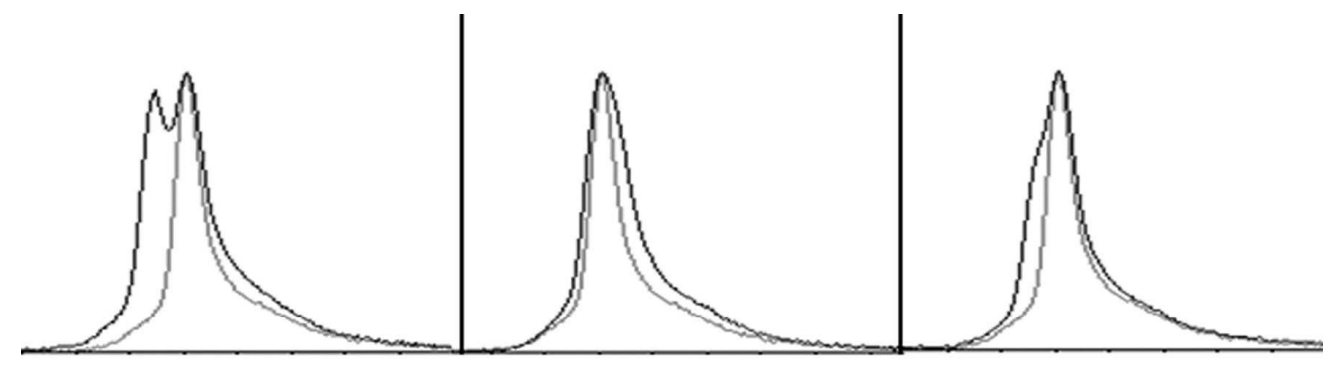

$226 \times 60 \mathrm{~mm}(600 \times 600 \mathrm{DPI})$ 


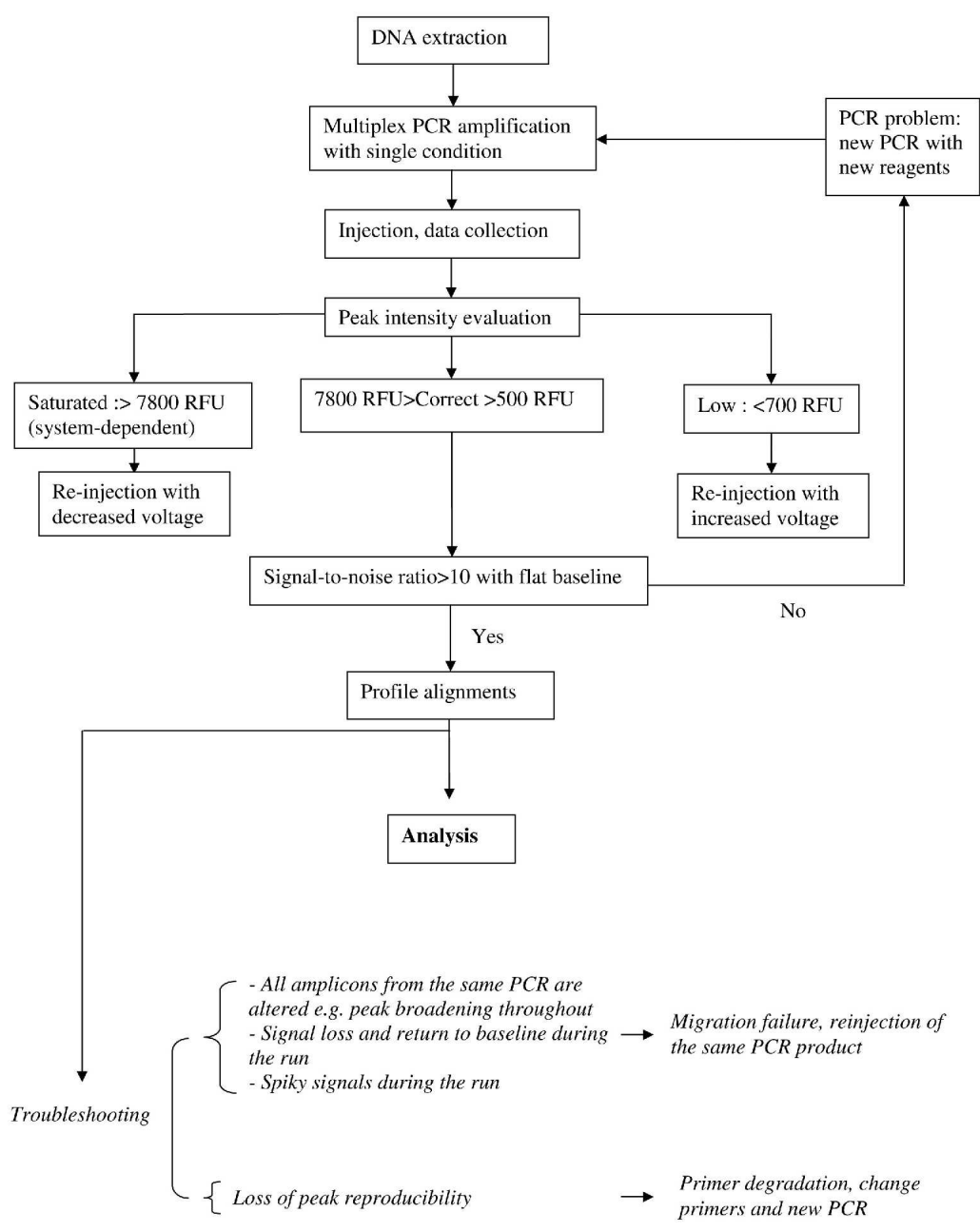

$209 \times 297 \mathrm{~mm}(600 \times 600 \mathrm{DPI})$

John Wiley \& Sons, Inc. 
A.

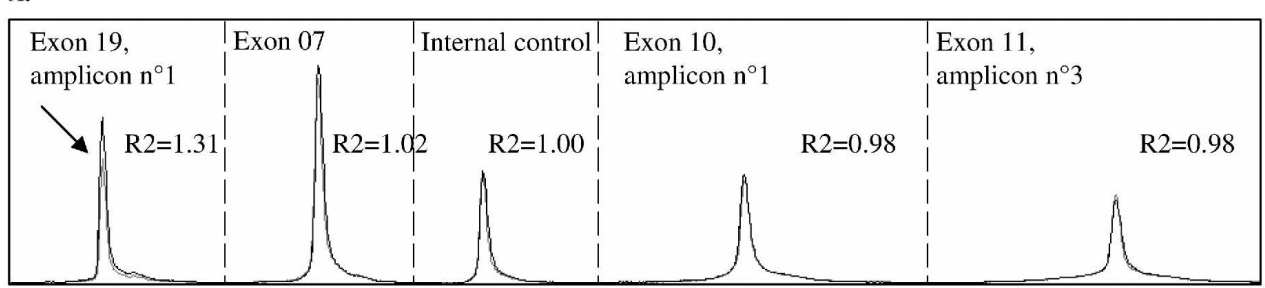

B.

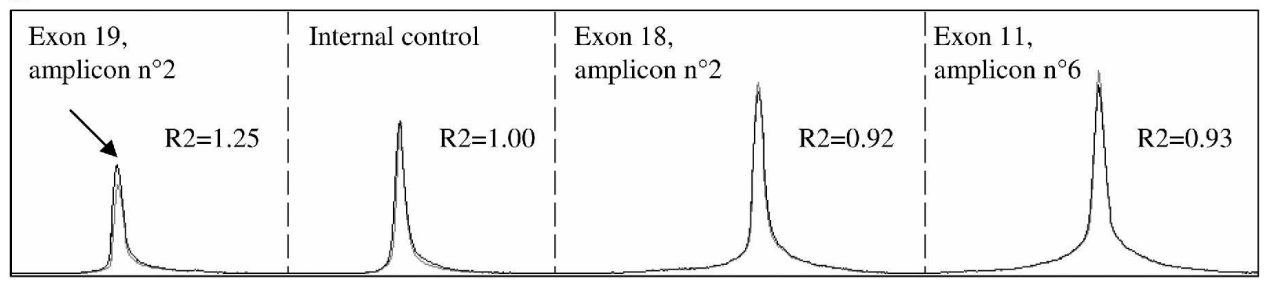

c.

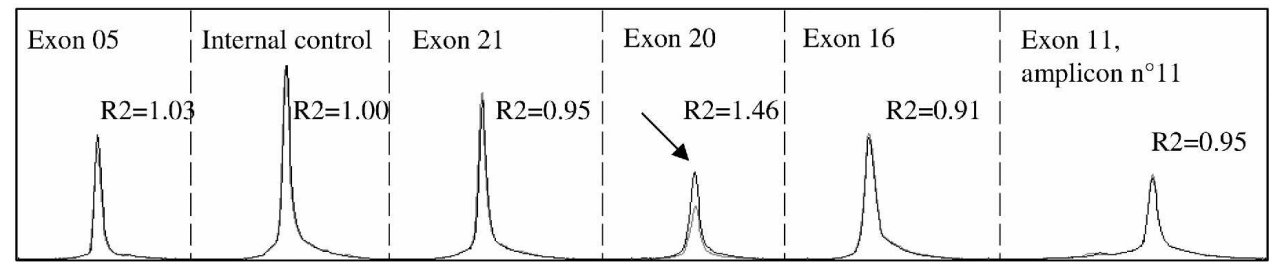

$240 \times 174 \mathrm{~mm}(600 \times 600 \mathrm{DPI})$

John Wiley \& Sons, Inc. 


\section{Supplementary Figure S1. In-house algorithm for UV scoring}

A restrictive definition of functional domains was used to avoid redundancy between "conservation across species" and "known functional domain" items. The amino-acid positions 24-64 (RING finger), 503-508 (SLN1), 607-615 (SLN2), 1189, 1457, 1524, 1542 (serine phosphorylation sites), 1649-1736 (BRCT1) and 1756-1855 (BRCT2) were therefore considered as functional domains for BRCA1. Functional domains for BRCA2 were as follows: amino-acid positions 18-105 (transactivation), 987-1069, 1198-1293; 1407-1498 ; 1501-1589; 1649-1735; 1822-1914; 1955-2035; 2036-2112 (BRC repeats), 3263-3269 (SLN1) and 3381-3385 (SLN2). Scores from 12 and above are considered "likely deleterious".

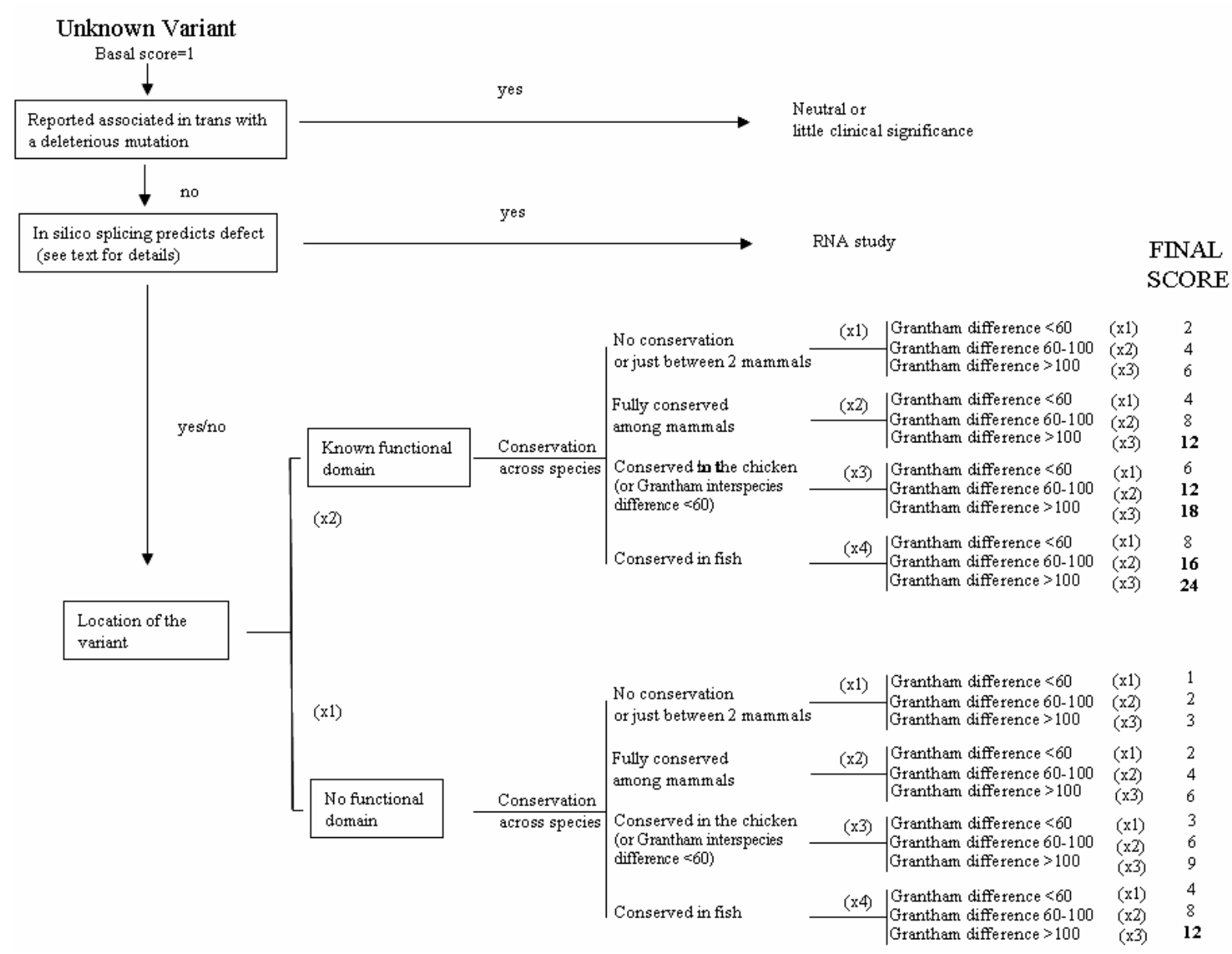




\section{Supplementary Table S1A. Deleterious mutations found on BRCAI}

Recurrence numbers are in brackets. Nucleotide position was numbered on the basis of the coding sequence NM_007294.2. Nucleotide numbering reflects cDNA numbering with +1 corresponding to the A of the ATG translation initiation codon in the reference sequence. The initiation codon is codon 1 .

\begin{tabular}{|c|c|c|}
\hline Site & Description & Expected Consequence \\
\hline Exons 1-2 & $\begin{array}{c}\text { c.-200-?_80+?del } \\
\text { (deletion of exons } 1 \text { and } 2 \text { ) }\end{array}$ & \\
\hline \multirow[t]{3}{*}{ Exon 2} & c. $1 \mathrm{~A}>\mathrm{G}(3)$ & p.Met1? \\
\hline & c.19_47del29 & p.Arg7_Asn16>CysfsX24 \\
\hline & c.68_69delAG (3) & p.Glu23ValfsX17 \\
\hline Intron 2 & c. $81-2 A>G$ & \\
\hline Exon 5 & c. $140 \mathrm{G}>\mathrm{A}$ & p.Cys47Tyr \\
\hline \multirow[t]{2}{*}{ Intron 5} & c. $212+3 \mathrm{~A}>\mathrm{G}$ & \\
\hline & c. $213-02 \mathrm{~A}>\mathrm{C}$ & \\
\hline Exon 7 & c.342_343delTC & p.Pro115X \\
\hline Exons 8 to 13 & $\begin{array}{c}\text { c.442-? }-4357+? \text { del } \\
\text { (deletion of exons } 8 \text { to } 13 \text { ) }\end{array}$ & \\
\hline Exon 9 & c.569_570insAACG & p.Val191ThrfsX3 \\
\hline \multirow[t]{30}{*}{ Exon 11} & c. $800 \mathrm{C}>\mathrm{G}$ & p.Ser267X \\
\hline & c.815_824dup 10 & p.Thr276AlafsX14 \\
\hline & c.843_846del4 & p.Ser282TyrfsX15 \\
\hline & c.928C $>\mathrm{T}$ & p.Gln310X \\
\hline & c.1016dupA & p.Val340GlyfsX6 \\
\hline & c.1121delC & p.Thr374AsnfsX2 \\
\hline & c.1953_1956del4 & p.Lys653SerfsX47 \\
\hline & c.2197_2201del5 & p.Glu733ThrfsX5 \\
\hline & c. $2269 \mathrm{delG}$ & p.Val757PhefsX8 \\
\hline & c.2308delT & p.Ser770HisfsX22 \\
\hline & c.2561_2565del5 & p.Ala854ValfsX47 \\
\hline & c.2952delT & p.Ile986SerfsX14 \\
\hline & c. 3285 delA & p.Lys1095AsnfsX14 \\
\hline & c.3377delC & p.Pro1126HisfsX3 \\
\hline & c. $3403 \mathrm{C}>\mathrm{T}$ & p.Gln1135X \\
\hline & c.3417delT & p.Ser1139ArgfsX16 \\
\hline & c.3428delCinsTA & p.Ser1143LeufsX6 \\
\hline & c.3481_3491del11 & p.Glu1161PhefsX3 \\
\hline & c. $3593 \mathrm{~T}>\mathrm{A}$ & p.Leu1198X \\
\hline & c.3648dupA & p.Ser1217IlefsX2 \\
\hline & c.3700_3704del5 & p.Val1234GlnfsX8 \\
\hline & c. $3748 \mathrm{G}>\mathrm{T}$ & p.Glu1250X \\
\hline & c.3753T $>A$ & p.Cys $1251 \mathrm{X}$ \\
\hline & c.3756_3759del4 & p.Ser1253ArgfsX10 \\
\hline & c.3771_3778del8 & p.Glu1257AspfsX7 \\
\hline & c.3839_3843del5ins4 & p.Ser1280X \\
\hline & c. $3841 \mathrm{C}>\mathrm{T}$ & p.Gln1281X \\
\hline & c. $3937 \mathrm{C}>\mathrm{T}$ & p.Gln1313X \\
\hline & c. $4065 \_4068 \mathrm{del} 4$ & p.Asn1355_Gln1356>LysfsX10 \\
\hline & $\begin{array}{c}\text { c.671-? } 4185+\text { ?del } \\
\text { (deletion of exons } 11 \text { and 12) }\end{array}$ & \\
\hline
\end{tabular}




\begin{tabular}{|c|c|c|}
\hline Site & Description & Expected Consequence \\
\hline Exon 12 & c.4165_4166delAG & p.Ser1389X \\
\hline \multirow[t]{3}{*}{ Exon 13} & c. $4201 \mathrm{C}>\mathrm{T}$ & p.Gln1401X \\
\hline & c. $4258 \mathrm{C}>\mathrm{T}$ & p.Gln1420X \\
\hline & c. $4327 \mathrm{C}>\mathrm{T}$ & p.Arg1443X \\
\hline \multirow[t]{2}{*}{ Exon 14} & c. $4372 \mathrm{C}>\mathrm{T}$ & p.Gln1458X \\
\hline & c. $4484 \mathrm{G}>\mathrm{T}(2)$ & p.Arg1495Met \\
\hline \multirow[t]{2}{*}{ Exon 16} & c. $4810 \mathrm{C}>\mathrm{T}$ & p.Gln1604X \\
\hline & c.4945_4947delAGAinsTTTT (2) & p.Arg1649PhefsX30 \\
\hline Intron 16 & c. $4986+6 \mathrm{~T}>\mathrm{C} \mathrm{(3)}$ & \\
\hline Exon 17 & c.5071dupA & p.Thr1691AsnfsX4 \\
\hline Exon 20 & c.5266dupC (6) & p.Gln1756ProfsX74 \\
\hline Exons 21 to 24 & $\begin{array}{c}\text { c.5278-? } * 1381+? \text { del } \\
\text { (deletion of exons } 21 \text { to } 24 \text { ) }\end{array}$ & \\
\hline Exon 21 & c. $5307 \mathrm{~T}>\mathrm{A}$ & p.Tyr1769X \\
\hline \multirow[t]{2}{*}{ Exon 24} & c. $5503 \mathrm{C}>\mathrm{T}$ & p.Arg1835X \\
\hline & c. $5541 \mathrm{C}>\mathrm{A}$ & p.Cys1847X \\
\hline
\end{tabular}




\section{Supplementary Table S1B. Deleterious mutations found on $B R C A 2$}

Recurrence numbers are in brackets. Nucleotide position was numbered on the basis of the coding sequence NM_000059.3. Nucleotide numbering reflects cDNA numbering with +1 corresponding to the A of the ATG translation initiation codon in the reference sequence. The initiation codon is codon 1 .

\begin{tabular}{|c|c|c|}
\hline Site & Description & Expected Consequence \\
\hline Exons 1 to 27 & $\begin{array}{l}\text { c. }(?+-227)\left(* 902_{-} ?\right) \text { del } \\
\text { (complete deletion) }\end{array}$ & \\
\hline \multirow[t]{2}{*}{ Exon 3} & c.145G>T (2) & p.Glu49X \\
\hline & c. $289 \mathrm{G}>\mathrm{T}$ & p.Glu97X \\
\hline Intron 6 & c. $516+1 \mathrm{G}>\mathrm{T}$ & \\
\hline \multirow[t]{6}{*}{ Exon 10} & c.1238delT & p.Leu413HisfsX17 \\
\hline & c.1310_1313del4 & p.Lys437IlefsX22 \\
\hline & c.1511_1512delCT & p.Ser504TyrfsX9 \\
\hline & c.1593dupA & p.Glu532ArgfsX3 \\
\hline & c.1773_1776del4 (3) & p.Ile591MetfsX22 \\
\hline & c.1813dupA & p.Ile605AsnfsX11 \\
\hline \multirow[t]{26}{*}{ Exon 11} & c.1929delG & p.Arg645GlufsX15 \\
\hline & c.2588dupA & p.Asn863LysfsX18 \\
\hline & c. $2612 \mathrm{C}>\mathrm{A}$ & p.Ser871X \\
\hline & c.2808_2811del4 (6) & p.Ala938ProfsX21 \\
\hline & c.2899_2900delCT & p.Leu967ArgfsX14 \\
\hline & c.3195delT & p.Asn1066IlefsX11 \\
\hline & c.3645_3646del2ins7 & p.Phe1216LysfsX14 \\
\hline & c.3744__3747del4 (2) & p.Ser1248ArgfsX10 \\
\hline & c.4136dupA & p.Ile1380AspfsX2 \\
\hline & c.4284dupT & p.Gln1429SerfsX9 \\
\hline & c. $4965 \mathrm{C}>\mathrm{A}$ & p.Tyr1655X \\
\hline & c.5197dupT & p.Ser1733PhefsX10 \\
\hline & c.5576_5579del4 & p.Ile1859LysfsX3 \\
\hline & c.5616_5620del5 & p.Lys1872AsnfsX2 \\
\hline & c. $5645 \mathrm{C}>\mathrm{A}$ & p.Ser1882X \\
\hline & c. $5682 \mathrm{C}>\mathrm{G}$ & p.Tyr1894X \\
\hline & c.5909C >A (2) & p.Ser1970X \\
\hline & c.5946delT (4) & p.Ser1982ArgfsX22 \\
\hline & c.6079dupA & p.Arg2027LysfsX22 \\
\hline & c.6082_6086del5 & p.Glu2028LysfsX19 \\
\hline & c.6275_6276delTT (2) & p.Leu2092ProfsX7 \\
\hline & c. $6359 \mathrm{C}>\mathrm{G}$ & p.Ser2120X \\
\hline & c.6373dupA & p.Thr2125AsnfsX4 \\
\hline & c.6405_6409del5 & p.Asn2135LysfsX3 \\
\hline & c.6644_6647del4 & p.Tyr2215SerfsX13 \\
\hline & c. $6656 \mathrm{C}>\mathrm{G}$ & p.Ser2219X \\
\hline
\end{tabular}




\begin{tabular}{|c|c|c|}
\hline Site & Description & Expected Consequence \\
\hline Exon 14 & c.7069_7070delCT & p.Leu2357ValfsX2 \\
\hline Exon 15 & c.7480C>T & p.Arg2494X \\
\hline \multirow{2}{*}{ Intron 15 } & c.7612A>T & p.Lys2538X \\
\hline \multirow{2}{*}{ Exon 16 } & c.7617+1G>T & \\
\cline { 2 - 3 } & c.7795_7797delGAA & p.Gln2561SerfsX5 \\
\cline { 2 - 3 } & c.7805G>C & p.Glu2599del \\
\hline \multirow{2}{*}{ Exon 18 } & c.8021delA & p.Lys2674ArgfsX2 \\
\cline { 2 - 3 } & c.8029_8030delGA & p.Glu2677LysfsX3 \\
\cline { 2 - 3 } & c.8032-8033dupAG & p.Asp2679GlyfsX16 \\
\cline { 2 - 3 } & c.8207delT & p.Leu2736ProfsX2 \\
\hline Exons 19 to 20 & c.8332-?_8632+?dup & p.Glu2850GlnfsX12 \\
\hline Exon 20 & c.8548_8551del4 & p.Tyr3009SerfsX7 \\
\hline Exon 23 & c.9026_9030del5 & p.Thr3033LeufsX29 \\
\cline { 2 - 3 } & c.9097delA & p.Arg3052Trp \\
\hline Exon 24 & c.9154C>T & p.Thr3085AsnfsX26 \\
\cline { 2 - 3 } & c.9253dupA & \\
\hline Intron 24 & c.9257-1G>A & \\
\hline \multirow{2}{*}{} & &
\end{tabular}


1

\section{Supplementary Table S2A. Unknown variants found on BRCA1}

Recurrence numbers are in brackets. Nucleotide position was numbered on the basis of the coding sequence NM_007294.2. Nucleotide numbering reflects cDNA numbering with +1 corresponding to the A of the ATG translation initiation codon in the reference sequence. The initiation codon is codon 1 .

\begin{tabular}{|c|c|c|}
\hline Site & Description & Expected Consequence \\
\hline Intron 1 & c. $-19-24 \mathrm{~A}>\mathrm{G}$ & \\
\hline \multirow[t]{2}{*}{ Intron 2} & c.81-178_167del12 (*) & \\
\hline & c. $81-14 \mathrm{C}>\mathrm{T}$ & \\
\hline Exon 3 & c. $92 \mathrm{~T}>\mathrm{A}$ & p.Ile31Asn \\
\hline \multirow[t]{2}{*}{ Intron 3} & c. $134+149 \mathrm{~A}>\mathrm{C}$ & \\
\hline & c. $135-27 \mathrm{~T}>\mathrm{A}$ & \\
\hline Exon 5 & c. $199 \mathrm{G}>\mathrm{T}$ & p.Asp67Tyr \\
\hline \multirow[t]{2}{*}{ Intron 6} & c. $301+55 \mathrm{G}>\mathrm{A}$ & \\
\hline & c.302-24_22delAAT & \\
\hline \multirow[t]{2}{*}{ Exon 7} & c. $314 \mathrm{~A}>\mathrm{G}$ & p.Tyr105Cys \\
\hline & c. $425 \mathrm{C}>\mathrm{A}$ & p.Pro142His \\
\hline Intron 7 & c. $441+52$ del12 (2) & \\
\hline \multirow[t]{4}{*}{ Exon 8} & c. $448 \mathrm{~A}>\mathrm{G}$ & p.Thr150Ala \\
\hline & c. $456 \mathrm{C}>\mathrm{T}(2)$ & p.Leu152Leu \\
\hline & c. $466 \mathrm{C}>\mathrm{A}$ & p.Leu156Ile \\
\hline & c. $536 \mathrm{~A}>\mathrm{G}(2)$ & p.tyr179Cys \\
\hline \multirow[t]{4}{*}{ Intron 8} & c. $547+3 \mathrm{~A}>\mathrm{T}(2)$ & \\
\hline & c. $548-34 \mathrm{~T}>\mathrm{C}$ & \\
\hline & c.548-58dupT & 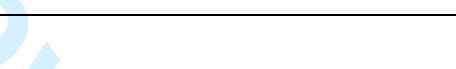 \\
\hline & c. $548-65 \mathrm{~A}>\mathrm{C}$ & 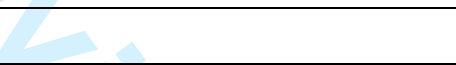 \\
\hline \multirow[t]{2}{*}{ Intron 9} & c. $593+76 \mathrm{C}>\mathrm{G}$ & C \\
\hline & c.594-34T $>C$ & \\
\hline Intron 10 & c. $670+85 \mathrm{~T}>\mathrm{C}(2)$ & 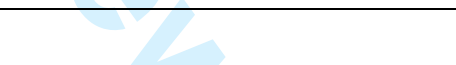 \\
\hline \multirow[t]{15}{*}{ Exon 11} & c. $981 \mathrm{~A}>\mathrm{G}(4)$ & p.Thr327Thr \\
\hline & c. $1456 \mathrm{~T}>\mathrm{C}(2)$ & p.Phe486Leu \\
\hline & c. $1487 \mathrm{G}>\mathrm{A}$ & p.Arg496His \\
\hline & c. $1541 \mathrm{C}>\mathrm{G}$ & p.Pro514Arg \\
\hline & c. $1648 \mathrm{~A}>\mathrm{C}(2)$ & p.Asn550His \\
\hline & c. $1866 \mathrm{G}>\mathrm{A}$ & p.Ala622Ala \\
\hline & c. $1940 \mathrm{G}>\mathrm{A}$ & p.Ser647Asn \\
\hline & c. $2352 \mathrm{G}>\mathrm{A}$ & p.Ser784Ser \\
\hline & c. $2458 \mathrm{~A}>\mathrm{G}$ & p.Lys820Glu \\
\hline & c. $2477 \mathrm{C}>\mathrm{A}(2)$ & p.Thr826Lys \\
\hline & c. $2518 \mathrm{~A}>\mathrm{T}$ & p.Ser840Cys \\
\hline & c. $2733 \mathrm{~A}>\mathrm{G}(4)$ & p.Gly911Gly \\
\hline & c. $2942 \mathrm{C}>\mathrm{T}$ & p.Pro981Leu \\
\hline & c. $3296 \mathrm{C}>\mathrm{T}$ & p.Pro1099Leu \\
\hline & c. $3302 \mathrm{G}>\mathrm{A}$ & p.Ser1101Asn \\
\hline
\end{tabular}




\begin{tabular}{|c|c|c|}
\hline & c. $3305 \mathrm{~A}>\mathrm{G}$ & p.Asn1102Ser \\
\hline & c. $3418 \mathrm{~A}>\mathrm{G}(4)$ & p.Ser1140Gly \\
\hline & c. $3600 \mathrm{G}>\mathrm{T}$ & p.Gln1200His \\
\hline Site & Description & Expected Consequence \\
\hline \multirow[t]{4}{*}{ Exon 11} & c. $3608 \mathrm{G}>\mathrm{A}$ & p.Arg1203Gln \\
\hline & c. $3640 \mathrm{G}>\mathrm{A}$ & p.Glu1214Lys \\
\hline & c. $3804 \mathrm{~T}>\mathrm{C}$ & p.Asn1268Asn \\
\hline & c. $3823 \mathrm{~A}>\mathrm{G}(4)$ & p.Ile1275Val \\
\hline Exon 12 & c. $4113 \mathrm{G}>\mathrm{A}(2)$ & p.Gly1371Gly \\
\hline \multirow[t]{3}{*}{ Intron 12} & c. $4185+3 \mathrm{~A}>\mathrm{T}$ & \\
\hline & c. $4185+21$ delTG & \\
\hline & c.4185+21_22dupTG & \\
\hline Exon 13 & c. $4255 \mathrm{G}>\mathrm{C}$ & p.Glu1419Gln \\
\hline Intron 13 & c. $4358-37 \mathrm{G}>\mathrm{A}$ & \\
\hline Exon 14 & c. $4445 \mathrm{~A}>\mathrm{G}$ & p.Asp1482Gly \\
\hline Exon 15 & c. $4636 \mathrm{G}>\mathrm{A}$ & p.Asp1546Asn \\
\hline \multirow[t]{2}{*}{ Intron 14} & c. $4485-32 \mathrm{C}>\mathrm{T}$ & \\
\hline & c. $4485-57 \mathrm{~T}>\mathrm{C}$ & \\
\hline \multirow[t]{2}{*}{ Intron 15} & c. $4675+31 \mathrm{C}>\mathrm{T}$ & \\
\hline & c. $4675+81 \mathrm{~T}>\mathrm{C}$ & \\
\hline \multirow[t]{3}{*}{ Exon 16} & c. $4691 \mathrm{~T}>\mathrm{C}$ & p.Leu1564Pro \\
\hline & c. $4812 \mathrm{~A}>\mathrm{G}$ & p.Gln1604Gln \\
\hline & c. $4840 \mathrm{C}>\mathrm{T}$ & p.Pro1614Ser \\
\hline Exon 17 & c. $4993 \mathrm{G}>\mathrm{C}$ & p.Val1665Leu \\
\hline \multirow[t]{2}{*}{ Intron 16} & c. $4987-20 A>G$ & \\
\hline & c. $4987-25 \mathrm{~A}>\mathrm{G}$ & \\
\hline \multirow[t]{3}{*}{ Intron 17} & c. $5074+107 \mathrm{C}>\mathrm{T}$ & \\
\hline & c.5074+108G>A (3) & 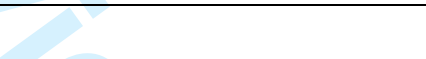 \\
\hline & c. $5075-74 \mathrm{C}>\mathrm{T}$ & 7 \\
\hline Exon 19 & c. $5177 \mathrm{G}>\mathrm{T}$ & p.Arg1726Ile \\
\hline \multirow[t]{3}{*}{ Intron 19} & c. $5193+64 \mathrm{~T}>\mathrm{G}$ & 20 \\
\hline & c. $5194-14 \mathrm{~T}>\mathrm{A}$ & \\
\hline & c.5194-165_162dup & \\
\hline \multirow[t]{2}{*}{ Exon 20} & c. $5203 \mathrm{G}>\mathrm{A}$ & p.Glu1735Lys \\
\hline & c.5213G $>A$ & p.Gly1738Glu \\
\hline Intron 20 & c. $5277+55 \mathrm{~A}>\mathrm{T}$ & \\
\hline \multirow[t]{6}{*}{ Intron 21} & c.5332+182dupA $(*)$ & \\
\hline & c. $5332+78 \mathrm{C}>\mathrm{T}$ & \\
\hline & c.5333-130T>C (2) & \\
\hline & c.5333-44A $>\mathrm{T}$ & \\
\hline & c. $5333-61 \mathrm{G}>\mathrm{C}$ & \\
\hline & c.5333-134C>A (4) & \\
\hline Intron 22 & c. $5406+63 \mathrm{G}>\mathrm{T}$ & \\
\hline Exon 23 & c. $5412 \mathrm{C}>\mathrm{T}(2)$ & p.Val1804Val \\
\hline
\end{tabular}




\begin{tabular}{|l|c|l|} 
Intron 23 & c. $5467+148 \mathrm{delT}$ & \\
\cline { 2 - 3 } & c.5468-10C $>\mathrm{A}(2)$ & \\
\hline
\end{tabular}

(*) these UVs were detected following allele drop-out (see text) 


\section{Supplementary Table S2B. Unknown variants found on BRCA2}

Recurrence numbers are in brackets. Nucleotide position was numbered on the basis of the coding sequence NM_000059.3. Nucleotide numbering reflects cDNA numbering with +1 corresponding to the A of the ATG translation initiation codon in the reference sequence. The initiation codon is codon 1 .

\begin{tabular}{|c|c|c|}
\hline Site & Description & Expected Consequence \\
\hline \multirow[t]{3}{*}{ Exon 2} & c. $-11 \mathrm{C}>\mathrm{T}(5)$ & \\
\hline & c. $-12 \mathrm{~T}>\mathrm{C}$ & \\
\hline & c. $64 \mathrm{G}>\mathrm{A}$ & p.Ala22Thr \\
\hline \multirow[t]{3}{*}{ Intron 2} & c. $67+62 \mathrm{~T}>\mathrm{G}(12)$ & \\
\hline & c. $67+82 C>G(14)$ & \\
\hline & c.68-7T>A (7) & \\
\hline \multirow{4}{*}{ Exon 3} & c. $122 \mathrm{C}>\mathrm{T}$ & p.Pro41Leu \\
\hline & c. $198 \mathrm{~A}>\mathrm{G}$ & p.Gln66Gln \\
\hline & c. $223 \mathrm{G}>\mathrm{C}(3)$ & p.Ala75Pro \\
\hline & c. $280 \mathrm{C}>\mathrm{T}$ & p.Pro94Ser \\
\hline \multirow[t]{7}{*}{ Intron 3} & c. $316+5 \mathrm{G}>\mathrm{C}$ & \\
\hline & c. $316+6 \mathrm{~T}>\mathrm{C}$ & \\
\hline & c. $316+12 A>G$ & \\
\hline & c. $316+13 A>G$ & \\
\hline & c. $316+57 \mathrm{C}>\mathrm{T}$ & \\
\hline & c. $317-12 \mathrm{G}>\mathrm{A}$ & \\
\hline & c.317-92delA & \\
\hline \multirow[t]{2}{*}{ Exon 4} & c. $324 \mathrm{~T}>\mathrm{C}$ & p.Asn108Asn \\
\hline & c. $400 \mathrm{C}>\mathrm{A}$ & p.Leu134Ile \\
\hline Intron 4 & c. $425+52 \mathrm{~A}>\mathrm{G}$ & A \\
\hline \multirow[t]{3}{*}{ Intron 5} & c. $475+3 \mathrm{~A}>\mathrm{T}$ & 2 \\
\hline & c. $476-5 \mathrm{C}>\mathrm{T}$ & \\
\hline & c. $476-24 \mathrm{~A}>\mathrm{G}$ & 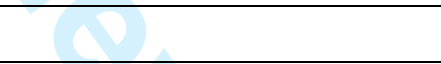 \\
\hline \multirow[t]{6}{*}{ Intron 6} & c. $516+21 \mathrm{~A}>\mathrm{T}(4)$ & 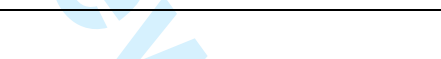 \\
\hline & c. $516+54 \mathrm{~T}>\mathrm{C}$ & 27 \\
\hline & c. $517-19 \mathrm{C}>\mathrm{T}(4)$ & \\
\hline & c.517-23_22delTA & \\
\hline & c. $517-74 \mathrm{G}>\mathrm{C}$ & \\
\hline & c.517-89G $>A$ & \\
\hline Exon 7 & c. $532 \mathrm{~A}>\mathrm{C}$ & p.Lys178Gln \\
\hline \multirow[t]{5}{*}{ Intron 7} & c. $631+18 \mathrm{G}>\mathrm{A}$ & \\
\hline & c. $631+25 \mathrm{C}>\mathrm{T}$ & \\
\hline & c. $631+66 \mathrm{C}>\mathrm{T}$ & \\
\hline & c. $632-16 \mathrm{~A}>\mathrm{C}$ & \\
\hline & c. $632-75 \mathrm{~T}>\mathrm{C}$ & \\
\hline \multirow[t]{2}{*}{ Intron 8} & c. $682-30 \mathrm{~A}>\mathrm{C}$ & \\
\hline & c. $682-32 A>G$ & \\
\hline \multirow[t]{2}{*}{ Exon 10} & c.943T $>A$ & p.Cys315Ser \\
\hline & c. $978 \mathrm{C}>\mathrm{A}$ & p.Ser326Arg \\
\hline
\end{tabular}

John Wiley \& Sons, Inc. 


\begin{tabular}{|c|c|c|}
\hline & c. $986 \mathrm{G}>\mathrm{C}$ & p.Arg329Thr \\
\hline & c. $1096 \mathrm{~T}>\mathrm{G}$ & p.Leu366Val \\
\hline & c. $1181 \mathrm{~A}>\mathrm{C}$ & p.Glu394Ala \\
\hline \multirow[t]{11}{*}{ Exon 10} & c. $1216 \mathrm{G}>\mathrm{A}$ & p.Ala406Thr \\
\hline & c. $1219 \mathrm{C}>\mathrm{G}$ & p.Gln407Glu \\
\hline & c. $1272 \mathrm{~A}>\mathrm{G}$ & p.Ser424Ser \\
\hline & c. $1275 \mathrm{~A}>\mathrm{G}$ & p.Glu425Glu \\
\hline & c. $1281 \mathrm{C}>\mathrm{A}$ & p.Asp427Glu \\
\hline & c. $1395 \mathrm{~A}>\mathrm{C}$ & p.Val465Val \\
\hline & c. $1514 \mathrm{~T}>\mathrm{C}$ & p.Ile505Thr \\
\hline & c. $1561 \mathrm{~T}>\mathrm{G}$ & p.Ser521Ala \\
\hline & c. $1786 \mathrm{G}>\mathrm{C}$ & p.Asp596His \\
\hline & c. $1788 \mathrm{~T}>\mathrm{C}(5)$ & p.Asp596Asp \\
\hline & c. $1792 \mathrm{~A}>\mathrm{G}(2)$ & p.Thr598Ala \\
\hline Intron 10 & c. $1910-43 \mathrm{~T}>\mathrm{C}$ & \\
\hline \multirow[t]{30}{*}{ Exon 11} & c. $1964 C>G$ & p.Pro655Arg \\
\hline & c. $1966 A>G$ & p.Thr656Ala \\
\hline & c. $2330 A>G$ & p.Asp777Gly \\
\hline & c. $2350 A>G$ & p.Met784Val \\
\hline & c. $2477 \mathrm{~A}>\mathrm{G}$ & p.Glu826Gly \\
\hline & c. $2538 \mathrm{~A}>\mathrm{C}(2)$ & p.Ser846Ser \\
\hline & c. $2550 A>G(2)$ & p.Gln850Gln \\
\hline & c. $2635 \mathrm{~T}>\mathrm{A}$ & p.Ser879Thr \\
\hline & c. $2803 \mathrm{G}>\mathrm{A}(4)$ & p.Asp935Asn \\
\hline & c. $2803 \mathrm{G}>\mathrm{C}$ & p.Asp935His \\
\hline & c. $2817 \mathrm{C}>\mathrm{T}$ & p.Thr939Thr \\
\hline & c. $3097 \mathrm{G}>\mathrm{T}$ & p.Asp1033Tyr \\
\hline & c. $3152 \mathrm{~T}>\mathrm{C}$ & p.Leu1051Ser \\
\hline & c.3264T >C (2) & p.Pro1088Pro \\
\hline & c. $3445 \mathrm{~A}>\mathrm{G}$ & p.Met1149Val \\
\hline & c. $3515 \mathrm{C}>\mathrm{T}(2)$ & p.Ser1172Leu \\
\hline & c. $3516 \mathrm{G}>\mathrm{A}(3)$ & p.Ser1172Ser \\
\hline & c. $3723 \mathrm{~T}>\mathrm{G}$ & p.Phe1241Leu \\
\hline & c. $3749 A>G$ & p.Glu1250Gly \\
\hline & c. $3869 \mathrm{G}>\mathrm{A}$ & p.Cys 1290Tyr \\
\hline & c.3949A $>\mathrm{T}(2)$ & p.Thr1317Ser \\
\hline & c. $4090 \mathrm{~A}>\mathrm{C}(5)$ & p.Ile1364Leu \\
\hline & c. $4164 \mathrm{~T}>\mathrm{C}$ & p.Thr1388Thr \\
\hline & c. $4199 \mathrm{~A}>\mathrm{G}$ & p.His1400Arg \\
\hline & c. $4241 \mathrm{C}>\mathrm{T}$ & p.Thr1414Met \\
\hline & c. $4242 \mathrm{G}>\mathrm{A}$ & p.Thr1414Thr \\
\hline & c. $4271 \mathrm{C}>\mathrm{G}(2)$ & p.Ser1424Cys \\
\hline & c. $4614 \mathrm{~T}>\mathrm{C}(2)$ & p.Ser1538Ser \\
\hline & c. $4677 \mathrm{~T}>\mathrm{C}$ & p.Phe1559Phe \\
\hline & c. $4686 \mathrm{~A}>\mathrm{G}$ & p.Gln1562Gln \\
\hline
\end{tabular}




\begin{tabular}{|c|c|c|}
\hline & c. $4850 \mathrm{G}>\mathrm{A}$ & p.Ser1617Asn \\
\hline & c. $4903 \mathrm{~T}>\mathrm{C}$ & p.Leu1635Leu \\
\hline & c. $5070 \mathrm{~A}>\mathrm{C}$ & p.Lys1690Asn \\
\hline \multirow[t]{22}{*}{ Exon 11} & c. $5268 \mathrm{~A}>\mathrm{G}$ & p.Val1756Val \\
\hline & c. $5312 \mathrm{G}>\mathrm{A}(2)$ & p.Gly1771Asp \\
\hline & c. $5418 \mathrm{~A}>\mathrm{G}(2)$ & p.Glu1806Glu \\
\hline & c. $5503 \mathrm{~A}>\mathrm{G}$ & p.Asn1835Asp \\
\hline & c. $5634 \mathrm{C}>\mathrm{T}$ & p.Asn1878Asn \\
\hline & c. $5688 \mathrm{~A}>\mathrm{G}$ & p.Ala1896Ala \\
\hline & c. $5704 \mathrm{G}>\mathrm{A}(2)$ & p.Asp1902Asn \\
\hline & c. $5741 \mathrm{G}>\mathrm{C}$ & p.Ser1914Thr \\
\hline & c. $5745 \mathrm{G}>\mathrm{A}$ & p.Thr1915Thr \\
\hline & c. $5778 \mathrm{~T}>\mathrm{G}$ & p.Ser1926Arg \\
\hline & c. $5785 \mathrm{~A}>\mathrm{G}$ & p.Ile1929Val \\
\hline & c. $5852 \mathrm{G}>\mathrm{A}$ & p.Ser1951Asn \\
\hline & c. $5896 \mathrm{C}>\mathrm{T}$ & p.His1966Tyr \\
\hline & c. $.5928 \mathrm{G}>\mathrm{T}$ & p.Gly1976Gly \\
\hline & c. $5937 \mathrm{C}>\mathrm{G}$ & p.Ser1979Arg \\
\hline & c. $5985 \mathrm{C}>\mathrm{T}$ & p.Asn1995Asn \\
\hline & c. $6215 \mathrm{C}>\mathrm{G}$ & p.Ser2072Cys \\
\hline & c. $6295 \mathrm{~A}>\mathrm{G}$ & p.Arg2099Gly \\
\hline & c. $6323 \mathrm{G}>\mathrm{A}(3)$ & p.Arg2108His \\
\hline & c.6338A>G (2) & p.Asn2113Ser \\
\hline & c. $6347 \mathrm{~A}>\mathrm{G}(3)$ & p.His2116Arg \\
\hline & c. $6553 \mathrm{G}>\mathrm{T}$ & p.Ala2185Ser \\
\hline Intron 11 & c.6842-20T>A & \\
\hline Exon 12 & c. $6853 \mathrm{~A}>\mathrm{G}(2)$ & p.Ile2285Val \\
\hline Intron 12 & c.6938-26T>C & \\
\hline Exon 13 & c. $6972 \mathrm{~T}>\mathrm{C}$ & pHis2324His \\
\hline \multirow[t]{3}{*}{ Intron 13} & c. $7007+18 \mathrm{~T}>\mathrm{A}$ & 2 \\
\hline & c. $7007+53 \mathrm{G}>\mathrm{A}$ & 20 \\
\hline & c. $7008-44 A>G$ & \\
\hline \multirow[t]{5}{*}{ Exon 14} & c. $7017 \mathrm{G}>\mathrm{C}(2)$ & p.Lys2339Asn \\
\hline & c. $7052 \mathrm{C}>\mathrm{G}$ & p.Ala2351Gly \\
\hline & c. $7082 \mathrm{~A}>\mathrm{G}$ & p.His2361Arg \\
\hline & c. $7242 \mathrm{~A}>\mathrm{T}$ & p.Ser2414Ser \\
\hline & c.7319A>G (3) & p.His2440Arg \\
\hline \multirow[t]{5}{*}{ Exon 15} & c.7469T $>C$ & p.Ile2490Thr \\
\hline & c.7478T $>\mathrm{G}$ & p.Met2493Arg \\
\hline & c. $7534 \mathrm{C}>\mathrm{T}$ & p.Leu2512Phe \\
\hline & c. $7559 \mathrm{G}>\mathrm{T}$ & p.Arg2520Leu \\
\hline & c. $7565 \mathrm{C}>\mathrm{T}$ & p.Ser2522Phe \\
\hline Intron 15 & c.7618-74A>G & \\
\hline \multirow[t]{2}{*}{ Intron 16} & c. $7805+46 \mathrm{C}>\mathrm{T}$ & \\
\hline & c. $7805+47 \mathrm{~A}>\mathrm{G}$ & \\
\hline
\end{tabular}




\begin{tabular}{|c|c|c|}
\hline & c. $7806-40 A>G$ & \\
\hline Exon 17 & c. $7975 \mathrm{~A}>\mathrm{G}$ & p.Arg2659Gly \\
\hline Intron 17 & c. $7976+35 \mathrm{C}>\mathrm{A}(2)$ & \\
\hline Intron 17 & c. $7976+57 \mathrm{G}>\mathrm{C}$ & \\
\hline \multirow[t]{3}{*}{ Exon 18} & c.7994A>G (2) & p.Asp2665Gly \\
\hline & c.8149G>T (2) & p.Ala2717Ser \\
\hline & c. $8182 \mathrm{G}>\mathrm{A}(2)$ & p.Val2728Ile \\
\hline Intron 18 & c. $8331+109 \mathrm{G}>\mathrm{A}(4)$ & \\
\hline Exon 19 & c.8460A>C (2) & p.Val2820Val \\
\hline \multirow[t]{4}{*}{ Intron 19} & IVS19+19A $>G$ & \\
\hline & c. $8487+47 \mathrm{C}>\mathrm{T}(8)$ & \\
\hline & c. $8487+82 \mathrm{G}>\mathrm{A}(3)$ & \\
\hline & c. $8488-52 A>G$ & \\
\hline \multirow[t]{3}{*}{ Exon 20} & c. $8503 \mathrm{~T}>\mathrm{C}$ & p.Ser2835Pro \\
\hline & c. $8567 \mathrm{~A}>\mathrm{C}(3)$ & p.Glu2856Ala \\
\hline & c. $8592 \mathrm{C}>\mathrm{T}$ & p.Ala2864Ala \\
\hline Intron 20 & c. $8633-4 \mathrm{~T}>\mathrm{A}$ & \\
\hline Intron 21 & c. $8754+75 A>G$ & \\
\hline \multirow[t]{2}{*}{ Exon 22} & c. $8850 \mathrm{G}>\mathrm{T}(2)$ & p.Lys2950Asn \\
\hline & c. $8904 \mathrm{C}>\mathrm{T}$ & p.Thr2968Thr \\
\hline Exon 23 & c. $9038 \mathrm{C}>\mathrm{T}$ & p.Thr3013Ile \\
\hline Intron 23 & c. $9117+44 \mathrm{G}>\mathrm{T}$ & \\
\hline Exon 24 & c. $9216 \mathrm{G}>\mathrm{A}$ & p.Val3072Val \\
\hline \multirow[t]{4}{*}{ Exon 25} & c. $9275 \mathrm{~A}>\mathrm{G}$ & p.Tyr3092Cys \\
\hline & c.9292T >C & p.Tyr3098His \\
\hline & c. $9371 \mathrm{~A}>\mathrm{T}$ & p.Asn3124Ile \\
\hline & c. $9373 \mathrm{C}>\mathrm{T}$ & p.Leu3125Phe \\
\hline Intron 25 & c. $9501+4 \mathrm{~A}>\mathrm{G}$ & \\
\hline \multirow[t]{5}{*}{ Exon 26} & c.9586A $>G$ & p.Lys3196Glu \\
\hline & c. $9606 \mathrm{G}>\mathrm{C}$ & p.Pro3202Pro \\
\hline & c. $9610 A>G$ & p.Thr3204Ala \\
\hline & c.9613_9614delGCinsCT & p.Ala3205Leu \\
\hline & c. $9613 \mathrm{G}>\mathrm{A}$ & p.Ala3205Thr \\
\hline \multirow[t]{5}{*}{ Intron 26} & c.9648+106delT (4) & \\
\hline & c. $9648+64 \mathrm{~T}>\mathrm{C}$ & \\
\hline & c. $9648+84 G>A(3)$ & \\
\hline & c.9649-20C>T (2) & \\
\hline & c.9649-65_62del4 & \\
\hline \multirow[t]{5}{*}{ Exon 27} & c.9730G>A (2) & p.Val3244Ile \\
\hline & c. $9738 \mathrm{C}>\mathrm{A}$ & p.Ala3246Ala \\
\hline & c. $9972 \mathrm{~A}>\mathrm{G}$ & p.Pro3324Pro \\
\hline & c. $10045 \mathrm{~A}>\mathrm{G}$ & p.Thr3349Ala \\
\hline & c. $10078 \mathrm{~A}>\mathrm{G}$ & p.Lys3360Glu \\
\hline
\end{tabular}

